\title{
Assessing the Potential of Climate Offset Programs
}

Link to publication record in Manchester Research Explorer

\section{Citation for published version (APA):}

Hahn, R., \& Giovanni, E. (2010). Assessing the Potential of Climate Offset Programs.

http://www.sci.manchester.ac.uk/

\section{Citing this paper}

Please note that where the full-text provided on Manchester Research Explorer is the Author Accepted Manuscript or Proof version this may differ from the final Published version. If citing, it is advised that you check and use the publisher's definitive version.

\section{General rights}

Copyright and moral rights for the publications made accessible in the Research Explorer are retained by the authors and/or other copyright owners and it is a condition of accessing publications that users recognise and abide by the legal requirements associated with these rights.

\section{Takedown policy}

If you believe that this document breaches copyright please refer to the University of Manchester's Takedown Procedures [http://man.ac.uk/04Y6Bo] or contact uml.scholarlycommunications@manchester.ac.uk providing relevant details, so we can investigate your claim.

\section{OPEN ACCESS}




\title{
Assessing the Potential of Climate Offset Programs
}

\author{
Robert Hahn and Emily Giovanni \\ January 2010 \\ Revised: October 2010
}

\section{Sustainable Consumption I nstitute}

The University of Manchester

188 Waterloo Place

Oxford Road

Manchester M13 9PL

Tel: +44 (0) 1612754030 


\title{
Assessing the Potential of Climate Offset Programs
}

\author{
Robert Hahn and Emily Giovanni*
}

January 2010

Revised: October 2010

\footnotetext{
* Mr. Hahn is director of the Sustainable Consumption Institute and professor of economics, University of Manchester, a senior visiting fellow at the Smith School, University of Oxford, and a senior fellow at the Georgetown Center for Business and Public Policy. Ms. Giovanni was a dual Master's Degree candidate at the School of Public and Environmental Affairs at Indiana University when this work was completed. We would like to thank Ken Richards for helpful comments. The views expressed in this paper are those of the authors and do not necessarily represent those of the institutions with which they are affiliated.
} 


\section{Executive Summary}

Several researchers have suggested using some type of offset program as a way of getting selected countries or sectors to reduce greenhouse gas emissions. The reason for this interest is that offset programs have the potential to reduce the costs of achieving a given environmental target. For our purposes, one can think of an offset as a property right generated outside of the main regulatory system, which can then be used in the regulatory system to reduce the compliance burden and compliance costs for affected parties.

This paper examines three international project-based mechanisms that have been used in the context of climate change. Two are offset programs implemented under the Kyoto Protocol - the Clean Development Mechanism and Joint Implementation. The third is a pilot program designed to test the implementation of these offset programs -- Activities Implemented Jointly.

Our purpose here is to provide an overview of these programs by reviewing the available literature. We find that the design of offsets programs will typically involve a tradeoff between cost savings and environmental quality, and that offset projects may reduce environmental quality because of problems with additionality and leakage. Moreover, there are likely to be significant challenges in scaling up offset programs.

We believe that offsets will probably continue to play a role in future greenhouse gas mitigation strategies. Given their potential for reducing environmental quality and their relatively high administrative and transaction costs, offsets are not a panacea. However, evidence suggests that they have the potential to lower mitigation costs, and that there may be some constructive ways to deal with environmental quality concerns. 


\title{
Assessing the Potential of Climate Offset Programs
}

\author{
Robert Hahn and Emily Giovanni*
}

\section{Introduction}

Several researchers have suggested using some type of offset program as a way of getting selected countries or sectors to reduce greenhouse gas emissions. The reason for this interest is that offsets have the potential to reduce the costs of achieving a given environmental target. For our purposes, one can think of an offset as a property right generated outside of the main regulatory system, which can then be used in the regulatory system to reduce the compliance burden and compliance costs of affected parties. For example, the U.S. might have a system that restricted the number of tons of carbon dioxide that industry could emit during a year. But it might also allow entities to undertake projects in other countries that could "offset" those emissions. The property rights generated by those offsets (say the right to emit one ton of carbon dioxide) could then be used within a U.S. cap-and-trade system.

Offsets are probably best understood in terms of a political compromise regarding environmental quality and costs (e.g., Hahn and Hester 1989). Because they can present some serious challenges in terms of monitoring, enforcement and assessing their impact on total emissions, they may not represent the most cost-effective way for addressing an environmental problem. Nonetheless, they may allow countries participating in a binding agreement, say on reducing net greenhouse emissions, to achieve low-cost reductions outside of the regulated region. Whether particular offset activities actually improve environmental quality, and how much, is an empirical matter, which we will address below.

This paper examines three international project-based mechanisms that have been used in the context of climate change. Two are offset programs implemented under the Kyoto Protocol, and the third is a pilot program designed to test the implementation of these offset programs.

\footnotetext{
* Mr. Hahn is a senior visiting fellow at the Smith School, Oxford, and a senior fellow at the Georgetown Center for Business and Public Policy. Ms. Giovanni is a dual Master's Degree candidate at the School of Public and Environmental Affairs at Indiana University. The views expressed in this paper are those of the authors and do not necessarily represent those of the institutions with which they are affiliated.
} 
The Protocol established binding caps on emissions for 37 nations. ${ }^{1}$ The nations with binding emission caps are termed Annex $1 .^{2}$ The overall goal of the Kyoto Protocol is to reduce the emissions of the Annex 1 countries to 5\% below the emission levels of 1990 during the first commitment period 2008 to 2012.

To reduce the costs of achieving emission reduction targets, Kyoto includes two basic flexibility mechanisms: emissions trading and offsets. In this report, we consider three programs that pertain to offsets: Activities Implemented Jointly (AIJ), the Clean Development Mechanism (CDM), and Joint Implementation (JI). AIJ projects do not generate credits that can be used to satisfy emission limits under the Kyoto Protocol, and it is technically not an offset program. However, it is highly relevant to this discussion because it is a pilot program implemented in advance of CDM and JI (which are both international offset programs under the Kyoto Protocol). AIJ provides an experience base upon which CDM and JI projects have subsequently been built. It also provides empirical evidence as to the environmental quality and cost impacts of projectbased offset programs for reducing climate change emissions.

CDM and JI are international project-based mechanisms involving the generation and market of offset credits. CDM projects are implemented in developing nations that are not subject to binding caps on emissions. These projects generate emission credits that may be used in Annex 1 nations to satisfy emission limits. JI projects are implemented in nations that have some binding emission limits under Kyoto. Host countries for JI projects are considered economies-in-transition, including Russia and Eastern European nations. Although these countries are also Annex 1 nations subject to emission limitations, these limitations are generally higher than current emissions (Jotzo and Michaelowa 2002; Korppoo and Moe 2008). This means that these countries do not have to reduce emissions in order to satisfy their commitments under the Kyoto Protocol. However, they still have many potential mitigation opportunities, making an offset market possible (Jotzo and Michaelowa 2002; Korppoo and Moe 2008; Wara 2008).

\footnotetext{
${ }^{1}$ See UNFCCC website for more details at http://unfccc.int/kyoto_protocol/items/2830.php

${ }^{2}$ Although these nations are also frequently referred to in the literature as Annex B nations.
} 
The original design of the CDM and JI mechanisms did not place a limit on the amount of a country's reduction that could be fulfilled with CDM and JI credits. In 2006, however, due to fears of future price collapses in EU emission credits, the commission took a more restrictive approach, with each country's maximum share fulfilled by CDM and/or JI dependent on their "reduction effort." Essentially, this metric placed a 50\% maximum on the share of reductions that could be satisfied using CDM and/or JI credits. ${ }^{3}$

A prime reason for reviewing existing international offset mechanisms is their potential to reach a greenhouse gas emission target at lower cost. Studies vary in their estimates of this potential, but some have suggested that they could, along with trading provisions (among Annex 1 nations) of the Kyoto Protocol, reduce global compliance costs by around $50 \%$ in the first commitment period between 2008 and 2012. ${ }^{4}$ However, this figure does not consider implementation issues such as transaction costs and administrative burdens, which are likely to be significant.

There is a need to assess implementation issues in practice in order to determine the feasibility of achieving real cost savings via offset programs. Furthermore, there is a great deal of concern in the literature that offset programs may seriously undermine the environmental quality goals of the Kyoto Protocol if emission reduction credits are awarded to projects that are not generating real, additional reductions. Therefore, before offset programs are expanded in scope, it is critical that policy makers take stock of actual experience with offsets.

Our purpose here is to provide an overview of these programs by reviewing the available literature. Section 2 provides an analysis of the available literature covering the environmental quality and cost impacts for the three existing international programs: a) the pilot AIJ program, b) CDM, and c) JI. We then provide an overview of the literature on scaling up offset programs in Section 3. Section 4 concludes and suggests areas for future research.

\section{Analysis of Three Offset Programs Based on the Kyoto Protocol}

\footnotetext{
${ }^{3}$ de Sepibus (2008), page 8. For an annotated bibliography of all sources referenced in this paper, see Appendix A.

${ }^{4}$ Cited in Frankhauser and Lavric (2003), page 418.
} 
The three programs analyzed are project-based international carbon offset programs implemented by the United Nations Framework Convention on Climate Change (UNFCCC). The first program, AIJ, is a pilot program for implementing projects. Some of these projects were subsequently registered under the Kyoto Protocol's two international offset markets, CDM and JI. For each program, we provide an overview of its structure and goals along with some descriptive statistics. We then ask the following questions:

i. What are the likely environmental quality impacts of these programs? More specifically, what is the degree of confidence possible that GHG reductions resulting from projects are additional relative to what would have happened in the absence of the program?

ii. What are the costs associated with implementing these programs? Costs can be broken down into two primary categories: 1) administrative costs (including processing, registration of projects, issuance of credits, and measurement and enforcement of emission reductions); and 2) transaction costs (including the costs of identifying partners and negotiating contracts).

iii. What is known about whether the offset program makes it more or less likely that countries that host offset projects will commit to future carbon emission reductions?

\section{A. Activities Implemented Jointly}

AIJ was implemented in advance of both CDM and JI as a pilot program for international project-based offset mechanisms, with projects beginning in the mid 1990s (Dolsak and Dunn 2006). Reductions generated by AIJ projects are not eligible for credits applicable to binding emission reduction commitments under the Kyoto Protocol. The program is expected to reduce approximately 509 million tons of $\mathrm{CO}_{2}$-equivalent over its lifetime. ${ }^{5}$

\footnotetext{
${ }^{5}$ Barrera and Schwarze (2004), page 354.
} 
According to the $7^{\text {th }}$ report on AIJ (UNFCCC 2006), there are 157 AIJ projects, hosted by 42 nations. About half of the AIJ projects are in the energy sector, while the other half consists of projects in forestry, agriculture, and landfills (with methane capture) (Dolsak and Dunn 2006). 86 AIJ projects are located in economies-in-transition and thus may include JI projects. Of the other projects, 57\% are in the Caribbean and Latin America, 26\% are in Asia and the Pacific, and $17 \%$ are in Africa. Sweden implements the largest number of projects (52), followed by U.S.

In the beginning of the AIJ program in the mid 1990s, projects were concentrated in the forestry sector. However, as it became clear during Kyoto negotiations that these projects would be controversial in moving to the $\mathrm{CDM} / \mathrm{JI}$ phase, non-forestry projects began to dominate the AIJ register (Michaelowa 2002).

AIJ projects are heavily influenced by preexisting aid and/or trade relationships between nations (Dolsak and Dunn 2006; Larson and Breustedt 2009). These relationships between host and investor countries help reduce transaction costs and allow investor countries to assess the attractiveness of projects in potential host countries (Dolsak and Dunn 2006; Larson and Breustedt 2009). By 2007, 316 bilateral or multilateral projects were registered, and these were virtually all characterized by preexisting relationships between countries. ${ }^{6}$ These preexisting relationships are more important in the location decision for investor countries than the potential for inexpensive reductions, since they allow nations to bypass the costs of establishing new bilateral relationships, which can be substantial (Dolsak and Dunn 2006).

\section{i. Environmental Quality Impacts}

The issue of environmental quality impacts of these project-based mechanisms is most frequently discussed in the context of additionality. Since emission credits generated by offset projects outside the regulated jurisdiction facilitate the increase of allowable emissions inside that jurisdiction, it is important that project emissions are real relative to what would have happened in the absence of the program. If the project was likely to be undertaken anyway, then it does not represent a real reduction. If credits are awarded for projects that would have

\footnotetext{
${ }^{6}$ Larson and Breustedt (2009)
} 
occurred anyway, and these credits are used to offset increased emissions elsewhere, environmental quality will be reduced. Because it is impossible to know precisely what would have happened in the counterfactual scenario (without the program), it is difficult to know which projects result in truly additional reductions.

Depending on the region and sector of the project in question, the verification of additionality can vary from relatively easy to extremely difficult. Chomitz (2000) identifies three classes of AIJ projects as they pertain to the demonstration of additionality:

- Class 1 - the most challenging cases for demonstrating additionality. For these projects, the sponsor is large and has good financing, the technology is well understood, and the investment yields direct monetary returns to the sponsor. Additionality is difficult to establish because this project would likely happen even in the absence of the offset program.

- Class 2-intermediate. The sponsor is small with limited funding, information about the technology is limited, and investments lead to direct but uncertain monetary returns.

- Class 3-easy to demonstrate additionality. These projects have direct financial costs and external, perhaps nonmonetary benefits, and are thus not likely to be undertaken in the absence of the offset program.

There is somewhat mixed evidence on additionality for AIJ projects, but most studies agree that project developers have largely failed to demonstrate additionality in many cases. Barrera and Schwarze (2004) conducted an evaluation of 152 AIJ activities, and found that at least 35\% of the projects were not additional. ${ }^{7}$ Most AIJ projects have arbitrary or unspecified baselines against which emission reductions are considered additional, further calling into question the environmental quality impacts of project-based mechanisms (Michaelowa 2002). In fact, most of the AIJ projects are not additional due to the non-specificity of baseline determinations and a lack of understanding of what would have happened in the absence of the project's implementation (Michaelowa 2002).

\footnotetext{
${ }^{7}$ Barrera and Schwarze (2004), page 365
} 
Because AIJ is a pilot project that does not generate credits that can be used to satisfy emission commitments, the failure to demonstrate additonality does not directly undermine the environmental quality goals of the Kyoto Protocol. However, the preceding analysis does raise two concerns. First, questionable claims of additionality have the potential to undermine the environmental quality targets of any large-scale offset program that does issue credits. Second, additionality assessments and verification of reductions are likely to be very important factors in the successful implementation of any large-scale offset program.

\section{ii. Costs}

Because AIJ projects do not generate any credits for use in carbon markets, experience with this program does not provide information on administrative costs associated with credit issuance (Frankhauser and Lavric 2003). But evidence generated from the program can identify and estimate average abatement costs, along with transaction and administrative costs that arise with project-based mechanisms. For example, Barrera and Schwarze (2004) evaluated 152 AIJ project reports and found abatement costs varying from $\$ 0.5 / \mathrm{CO}_{2}$ for land use, land use change, and forestry (LULUCF) projects in Latin America to $\$ 11.7 / \mathrm{t} \mathrm{CO}_{2}$ for energy efficiency projects in Eastern Europe. ${ }^{8}$ The average abatement cost for these projects was $\$ 5.1 / \mathrm{t} \mathrm{CO}_{2} \cdot{ }^{9}$ In their analysis of Dutch AIJ projects, Gupta et al. (2008) found costs in the same magnitude-ranging from $\$ 2.8 / \mathrm{CO}_{2}$ in Vietnam to $\$ 40.7 / \mathrm{CO}_{2}$ in Costa Rica. ${ }^{10}$

The above figures represent estimates for abatement cost, which are useful for nations and industries deciding whether to undertake specific offset projects. However, it is also useful to have an appreciation of transaction costs and administrative costs-because these will also affect the volume of offsets that are generated. For the purposes of this report, transaction costs include the costs of contracting between parties for implementing a project; administrative costs include the costs of measuring, enforcing, and validating the contracts and issuing credits.

\footnotetext{
${ }^{8}$ See Figure 1 in Barrera and Schwarze (2004), page 363.

${ }^{9}$ In what follows, all currency figures are presented directly from the studies cited, and have not been adjusted to a particular year dollar.

${ }^{10}$ Gupta et al. (2008) analyzed five AIJ projects implemented by the Dutch. Cost figures converted from euros. All five projects were renewable energy projects, and had emission reductions ranging from negligible (in China) to $55 \mathrm{kt} \mathrm{CO}_{2}$ per year (in Vietnam).
} 
There is a wide variety of definitions of administrative costs and transaction costs in the literature, making comparisons of empirical results difficult. For example, Fichtner et al. (2003), in their evaluation of AIJ project transaction costs, focus on the costs that accrue to private investors in projects, including the costs of establishing projects in foreign nations, and the costs of obtaining certification and credits. They analyzed 64 registered AIJ projects that provided information about production and transaction cost components of total costs. They find that transaction costs constitute a higher than expected proportion of total costs, with a range of 6$53 \%$ of total project costs. ${ }^{11}$ Additionally they found that the percentage of total cost taken up by transaction costs is higher for renewable energy projects than for energy efficiency projects (20\% and $13 \%$ respectively), and that economies of scale are apparent for total costs, production costs, and transaction costs (larger projects have lower per-ton costs). ${ }^{12}$

Michaelowa and Jotzo (2003) evaluate transaction costs reported from 51 Swedish AIJ projects. Because of the reporting format by the Swiss government on these projects, their definition of transaction costs include four categories: technical assistance, follow up, reporting and administration. Their definition thus differs from the one used above. However, their results do not include any consideration for external validation and certification (since AIJ projects do not earn credits) which may be significant factors in the administrative costs of the offsetgenerating CDM and JI programs. Like Fichtner et al., Michaelowa and Jotzo also found that economies of scale are an important determinant of transaction costs. They find that transaction costs are $20.5 \%$ of total project costs for energy efficiency projects, and $14.4 \%$ of renewable energy project costs, which tend to be larger-scale projects in their analysis. As shown in Table 1 , large projects that reduce over 10,000 tonnes $\mathrm{CO}_{2}$ /year have the smallest transaction costs-between $€ 1.3$ and $€ 1.8$ per tonne $\mathrm{CO}_{2}$. The smallest projects, less than 100 tonnes $\mathrm{CO}_{2}$ per year, have the highest transaction costs--between $€ 80$ and $€ 124$ per tonne $\mathrm{CO}_{2}{ }^{13}$

\section{iii. Impact on Developing Nations Setting Nationwide Targets}

\footnotetext{
${ }^{11}$ Fichtner et al. (2003), page 252.

${ }^{12}$ Fichtner et al. (2003), page 253.

${ }^{13}$ Michaelowa and Jotzo (2003), page 6.
} 
Because AIJ doesn't contribute to emission reduction requirements under Kyoto, it is not likely to have a substantial impact on the likelihood of climate commitments by developing nations. However, it is a key determinant of whether developing nations and economies-intransition are likely to participate in the offset mechanisms that do generate credits under Kyoto, since participation in AIJ builds the institutional capacities of these host countries (Frankhauser and Lavric 2003).

\section{B. Clean Development Mechanism}

$\mathrm{CDM}$ is a project-based mechanism that allows credits from emission reductions in developing nations (which have no emission reduction commitments) to generate certified emission reductions (CERs, equal to 1 tonne $\mathrm{CO}_{2}$-equivalent each), which can be used by Annex 1 countries to meet their emission reduction commitments under the Kyoto Protocol (Hepburn 2007). The goal of the mechanism is to reduce the overall costs of complying with emission reduction commitments by allowing reductions to occur where they are least-cost. In addition to the goal of least-cost carbon reductions, the second goal stated for CDM is sustainable development, which is not defined within the CDM framework. Rather, it is left to the discretion of the host nation to decide what activities qualify as having sustainable development benefits (Wara 2008; Nussbaumer 2009). Common metrics by which sustainable development goals are measured in the literature include: the formation of human capital, transfer of technology to host countries, capital transfers, improvement of income distribution, and reduction of local pollution (Michaelowa 2002).

The CDM market plays a very large role in the emission reduction commitments under the Kyoto Protocol. As of January 2008, there were 895 projects registered under the program, and 1,150 million tonnes of $\mathrm{CO}_{2}$ equivalent were registered to be delivered via $\mathrm{CDM}$ by the end of the first commitment period in 2012. ${ }^{14}$ According to the United Nations Framework Convention on Climate Change (UNFCCC), CDM is ultimately expected to generate over 2.7 billion tonnes of $\mathrm{CO}_{2}$-equivalent reductions through 1,839 registered projects within the first

\footnotetext{
${ }^{14}$ Wara (2008), page 21.
} 
commitment period of the Kyoto Protocol, 2008-2012. ${ }^{15}$ This represents approximately 3.3\% of the 1990 emission levels of Annex 1 countries each year during the first commitment period. ${ }^{16}$ The market for CER credits was worth over $€ 12$ million (\$17 million) in 2007. ${ }^{17}$

Most projects implemented under CDM to date have been concentrated in a relatively small number of countries, particularly China and India (Hepburn 2007), and in countries that already receive a high proportion of foreign aid (Ellis et al. 2007). The majority of projects to date have been concentrated in three areas: renewable electricity generation, reduction of methane emissions, and decomposition of gases from industrial processes (Ellis et al. 2007). Figure 1 shows a breakdown of projects in the pipeline for the first commitment period (20082012), and shows that most of the CER credits generated are attributed to large-scale, non- $\mathrm{CO}_{2}$ reducing projects. Examples include the capture of HFC- $23^{18}$ from refrigerant production, which was selected, in part, because of economies of scale (Wara 2008). These large-scale non- $\mathrm{CO}_{2}$ projects generate a large quantity of credits since most of the targeted greenhouse gases are more potent than $\mathrm{CO}_{2}$, and thus receive more credits per tonne reduction.

$\mathrm{CDM}$ has not been successful at inducing long-term $\mathrm{CO}_{2}$ emission reductions from capital-intensive projects. Several factors discouraged such investments. First, CER prices have remained relatively low, in the range of $\$ 3-6 / \mathrm{t} \mathrm{CO}_{2} \cdot{ }^{19}$ These prices are not sufficient to induce projects that have long lead times, or those with high capital costs such as large-scale renewable energy projects. Additionally, profit margins are narrow due to the eligibility requirements, which dictate that projects that are profitable in the absence of CER credits be categorized as business-as-usual, and are thus not eligible (Chadwick 2006).

\section{i. Environmental Quality Impacts}

\footnotetext{
${ }^{15}$ UNFCCC (2009) www.cdm.unfcc.int/index.html

${ }^{16}$ Wara (2008), page 21.

${ }^{17}$ Streck and Lin (2008), page 420.

18 The capture of HFC-23 and its implications for environmental quality impacts of CDM is discussed in more detail in the Environmental Quality Impacts section that follows.

${ }^{19}$ Ellis et al. (2007), page 20.
} 
Several concerns have been raised about whether CDM projects result in actual emission reductions. If CERs are generated through projects that would have occurred anyway, environmental integrity and reduction commitments will be undermined through CDM (Greiner and Michaelowa 2003). The empirical evidence on CDM to date suggests that the program is leading to widespread strategic behavior, which may ultimately undermine the environmental quality targets of the Kyoto Protocol (Wara 2008). For example, to maximize the revenues generated by CER sales, project investors have incentives to overestimate the emission reductions that occur from CDM projects (Greiner and Michaelowa 2003). Similarly, since developing nations don't have emission commitments under Kyoto, they have clear incentives to overestimate business-as-usual emission projections to attract investors and maximize revenues from CER generation (Chadwick 2006). Such strategic behavior calls into question the additionality of projects implemented under CDM.

China provides an example. There, all renewable energy projects are considered eligible for CDM credits, even though that country's energy portfolio already calls for the expansion of these technologies to meet growing demand (Wara and Victor 2008). This means that projects that would have occurred even in the absence of CDM are receiving emission reduction credits. In this case, CDM is leading to increased claims for credit (Wara 2008). Therefore, the credits that Annex 1 countries purchase to satisfy reduction credits do not represent actual reductions relative to the likely business as usual scenario.

Another example of additionality problems associated with CDM projects is the proliferation of HFC-23 reduction projects in China (Wara and Victor 2008; Wara 2008). HFC23, a by-product of refrigerant production, is a greenhouse gas that is several times more potent than carbon dioxide. Reductions can occur at very low cost, and voluntary capture and destruction has been occurring in the United States and Europe for years. Plants in developing nations have until recently vented the pollutant into the atmosphere. Thus, very inexpensive capture and destruction projects can generate a large quantity of valuable carbon credits at very low cost, if the baseline assumes that all plants will vent all HFC-23 generated as a byproduct of production. In fact, the carbon credits generated by capturing and destroying HFC-23 are more valuable than the refrigerants that generate the pollution-meaning that manufacturers have 
quickly become CDM credit merchants with a side business in refrigerant production. This mechanism gives them an incentive to produce more of the refrigerant in order to generate HFC23. which they then capture and destroy at low cost to earn carbon credits for the CDM market. HFC-23 may be a unique example, but it illustrates the serious problems that can occur in establishing baselines under CDM.

Several empirical studies have attempted to evaluate the likelihood that CDM projects are truly additional. Sutter and Parreno (2007) evaluate 16 registered CDM projects in 9 countries, finding that $72 \%$ of CERs are likely to represent truly additional reductions. ${ }^{20}$ Most of the CERs are generated by the largest projects. Of the 16 projects evaluated, 11 had low probabilities of representing truly additional reductions. In other words, the largest projects are more likely to be truly additional, while the smaller, more numerous projects, are not.

Schneider (2009) assessed 93 CDM projects that were sampled from the 768 projects registered as of July 2007 to evaluate the methodologies used to demonstrate additionality. For each of the four methods commonly used, between $30 \%$ and $90 \%$ of the projects did not even provide sufficient information to determine whether additionality was credible. ${ }^{21}$ Similarly, Michaelowa and Purohit (2007) evaluate 52 CDM projects in India, finding that only about half of the projects even considered alternative projects in their additionality assessment. ${ }^{22}$ The authors assess 19 of the projects in more detail, and find that fewer than half of the large projects provide sufficient information about additionality in their documentation.

Additionality is usually measured with respect to the project itself. There is also an important issue related to possible leakage, when emission reduction benefits in one nation are displaced by higher emissions in another nation that is not subject to emission commitments (Kallbekken et al. 2007). Murray et al. (2007) define leakage as "when a carbon project restricts emission generating activity in one place (the project) only to shift the activity (and emissions) to some other location outside the project boundary." ${ }^{23}$ If forest protection in one area simply

\footnotetext{
${ }^{20}$ Sutter and Parreno (2007), page 85.

${ }^{21}$ Schneider (2009), throughout paper.

${ }^{22}$ Michaelowa and Purohit (2007), abstract.

${ }^{23}$ Murray et al. (2007), page 133.
} 
increases deforestation elsewhere, there is no net decrease in emissions (Schwarze et al. 2002), and if the protection is awarded CERs, environmental quality will be reduced.

Some models of leakage suggests that $5-20 \%$ of the emission reductions required of Annex 1 countries are likely to be undermined by leakage. ${ }^{24}$ Other models suggest even higher leakage rates of up to $90 \%$ or $100 \%{ }^{25}$ Leakage is a significant concern in the context of land use, land use change, and forestry (LULUCF) projects. Due partly to concerns about leakage, CDM does not currently allow avoided deforestation as an eligible activity for CER generationrestricting land use projects to reforestation and afforestation. Additionally, the quantity of credits generated by these activities and used to satisfy emission limitations are restricted. Each Annex 1 country can satisfy only 1\% of its base year (1990) emission level per year during the first commitment period (Schwarze et al. 2002).

Other non-LULUCF projects are also subject to leakage. For example, leakage could account for $10-20 \%$ of emission reductions generated by energy projects. ${ }^{26}$ However this is expected to be a less significant factor for non-land based sectors. Additional carbon prices are not likely to displace many industries to alternative nations (Mattoo et al. 2009). For example, a recent study estimated that a $17 \%$ reduction in emissions in the United States and Europe would increase emissions in low income countries by only about $1 \% .{ }^{27}$

\section{ii. Costs}

Some preliminary empirical evidence suggests that CDM may be significantly less costeffective than hoped. For example, abating all the HFC-23 emissions in the developing world is estimated to cost about \$31 million per year. However, due to the subsidy effect of the CDM mechanism and the strategic behavior discussed above, Annex 1 countries paid around €250-750 million to abate these emissions in $2005^{28}$ —achieving the same outcome at a substantially higher

\footnotetext{
${ }^{24}$ Cited in Murray et al. (2004), page 111 and Kalbekken et al. (2007), page 4162.

${ }^{25}$ Murray et al. (2007); results limited to LULUCF projects

${ }^{26}$ Cited in Schwarze et al. (2002), page 1688.

${ }^{27}$ Mattoo et al. (2009), page 3.

${ }^{28}$ Wara (2008), page 35.
} 
cost. The prices paid for credits in the CER market are approximately ten times the marginal cost of HFC removal (Hepburn 2007).

There is little other large-scale empirical evidence about the cost-effectiveness of CDM overall. Because the purpose of CDM is to reduce the overall costs of meeting emission reduction commitments, evaluations of cost are an integral consideration for nations subject to emission reduction commitments. However, since each country has a different approach to calculating costs and revenues, it can be very difficult to compare project abatement costs (Michaelowa 2002). Instead, the cost discussions in the CDM literature focus on two types of costs: transaction costs and administrative costs. As with AIJ analyses, different authors frequently use different definitions. Chadwick (2006) defines transaction costs as the components of the CER price that are not attributable to the physical process of removing $\mathrm{CO}_{2}$ from the atmosphere or the level of demand for CERs which has the net result of lumping transaction costs and administrative costs together. In contrast, other authors have more detailed descriptions of what costs denote transaction costs and further disaggregate them into different

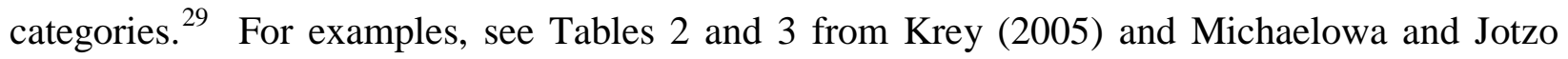
(2003), respectively. These tables demonstrate the wide variety of methods for disaggregating transaction costs and administrative costs used in the literature. While Krey (2005) groups costs according to the phase of implementation, Michaelowa and Jotzo (2003) have more categories and focus more on distinguishing which stakeholder bears which costs.

Because of its project-based structure, CDM and other offset programs are likely to have substantially higher transaction costs than a straightforward cap-and-trade program (Michaelowa and Jotzo 2005). Also, for authorizing individual CDM projects, each country has to set up an individual Designated National Authority. As a result, administrative costs vary widely across nations according to the procedures designated by that authority (Michaelowa and Jotzo 2003). For example, Thailand has decided that every individual project must be approved by a cabinet, suggesting that administrative costs are particularly high there (Michaelowa and Jotzo 2003).

\footnotetext{
${ }^{29}$ Also, for a more detailed discussion of transaction costs definitions across the literature, see Krey (2005).
} 
According to several authors, the CDM administrative body (the Executive Board) is slow and unpredictable in both timing and quantity, making the process unable to respond quickly to price shocks in the credit market (Wara and Victor 2008). As requests for CER credit issuance have increased dramatically since the outset of the CDM program, it has become increasingly difficult for the Executive Board to keep up. Thus, there is frequently a creditissuance bottleneck at the last stage of the process.

The administration of the CDM under the Executive Board faces additional criticism from various parties (Streck and Lin 2008). Executive Board decisions tend to be unpredictable and often come as surprises to participants, and there is no process for appealing decisions. The Board also faces criticisms for unnecessary delays-it takes between 6 months and two years for new methodologies to be approved. Factors increasing the risks of inconsistency in Board processes and decisions include: 1) lack of institutional memory due to the rotation of Board members, 2) processes driven by politics rather than a technocratic execution of the rules, and 3) insufficient technical expertise for handling complex issues (Streck and Lin 2008).

Information gathering by regulatory authorities is another significant cost of CDM administration. The Executive Board is called on to make decisions requiring significant technical expertise across a wide range of fields and countries (Wara 2008). There is an asymmetry of information; host countries have strong incentives to overstate efforts, and it is very difficult for regulators to confirm their claims (Wara and Victor 2008). Additionally, conflicting views within host countries can lead to continuous and long negotiations among various authorities and agencies. For example, local authorities have approved projects without securing national approval, which creates serious questions about the legitimacy of the projects (Michaelowa 2002).

The transaction costs and administrative costs associated with CDM are a primary concern in the literature, and may constitute significant barriers to large-scale implementation of offset programs. In an evaluation of 15 CDM projects in India, Krey (2005) found transaction costs ranging from $\$ .062$ to .470 per ton $\mathrm{CO}_{2}{ }^{30}$ In absolute terms, this is $\$ 57,193$ to $\$ 481,849$

\footnotetext{
${ }^{30}$ Krey (2005), page 2391.
} 
per project. However, these are likely to be underestimates, because these projects include several cost components that were not calculated due to lack of data. Also, approval costs are not included for any of the projects, because the Indian government does not yet have a Designated National Authority established. The study also broke transaction costs down by component. They found that some categories (such as buyer location and negotiation costs) have an effective "ceiling" which limits how high these costs get (irrespective of how expensive the project is). Other cost categories such as Project Design Documentation costs continue to take up a larger share of administrative costs for larger projects, with no apparent limit to how high these costs can get (Krey 2005). Table 4 provides the author's breakdown of transaction costs and the ranges of costs determined for each measured category. It shows that the range of costs are different for different categories of transaction costs. Overall, consistent with the findings described for AIJ projects above, economies-of-scale is the most important factor in transaction cost determinations (Krey 2005).

\section{iii. Impact on Developing Nations Setting Nationwide Targets}

Some commentators have argued that CDM may make it more likely that developing nations will eventually agree to nationwide targets on carbon dioxide or greenhouse gas emissions. For example, Ellis et al. (2007) argue that a long-term international commitment to a mechanism like CDM may actually encourage more countries to make commitments early on, so that they can take advantage of low-cost reductions at the outset instead of leaving the lowest cost reductions available for CDM investors. ${ }^{31}$ A related argument is that offsets may allow developing nations to develop institutional capabilities, which could increase their demand for reducing climate change emissions (Ellis 2007). However, while offsets may affect the demand for environmental quality in a country, the size of the effect is likely to be small. Rather than encouraging countries to make binding commitments, the CDM as implemented currently is likely to have the opposite effect.

A country will typically weigh the costs and benefits of entering into a climate agreement with binding targets. Consider three possibilities for a developing country: 1) it has no binding

\footnotetext{
${ }^{31}$ Ellis et al. (2007), page 27.
} 
target; 2) it has no binding target and uses CDM; or 3) it has a binding target. From the perspective of the developing country, purely on narrow economic grounds, situation 2 is likely to be preferable to 1 because CDM increases revenues coming into the country without imposing any significant costs. At the same time, CDM actually raises the opportunity cost for that country of entering into a binding agreement at a given level - that is option 3 becomes relatively less attractive to the developing country. The reason is that CDM serves as an effective subsidy to the developing country. In this sense, CDM may create perverse incentives, since governments in developing countries have incentives not to impose emission restrictions if it means that they can set a relaxed baseline and attract lucrative CDM investments (Dutschke 2000; Hepburn 2007; Wara and Victor 2008). Figueres (2006) discusses several Latin American examples of this phenomenon, wherein governments have hesitated to implement environmental policies for fear of invalidating potentially lucrative CDM projects underway in their nations.

While offsets may make it less likely that a country not participating in an agreement will join an agreement later on, they may increase the likelihood that some countries will participate in an agreement at the outset. This is because offsets can lower the cost of achieving the stated target for those countries that agree to a binding target. This practical advantage of offsets should not be ignored.

\section{Joint Implementation}

Like CDM, JI is a project-based mechanism that generates emission reduction credits that can be used by Annex 1 countries to satisfy emission reduction commitments. However, JI is about one-tenth the size of the larger CDM market (Wara and Victor 2008), with 89 registered projects. ${ }^{32} \mathrm{JI}$ is distinguished from CDM because the host countries are countries that also have emission reduction commitments under the Kyoto Protocol. In principle, Annex 1 countries pay for reductions additional to what would have occurred in other Annex 1 countries. They can then use the resulting credits to satisfy their own commitments (Wara 2008).

\footnotetext{
${ }^{32}$ See UNFCCC (2009) www.cdm.unfcc.int/index.html
} 
Countries hosting JI projects are primarily Russian and Eastern European countries. These host countries are often referred to as economies-in-transition, and have much more flexibility in their emissions than other Annex 1 countries, because their current emissions are in some cases already lower than they were in 1990 - the year against which emission reductions are measured under Kyoto (Frankhauser and Lavric 2003; Wara 2008). This is due to the economic downturn in the 1990s in these countries that led to substantial emission reductions, causing these nations' emission limits under the first commitment period to actually exceed their projected emissions (Jotzo and Michaelowa 2002). For example, Ukraine’s greenhouse gas emissions are approximately 45\% of what they were in $1990 .^{33} 19 \mathrm{JI}$ projects have been implemented in Ukraine-second only to Russia—and are expected to generate $49.8{\mathrm{Mt} \mathrm{CO}_{2}-}^{-}$ equvalent reduction during the first commitment period. ${ }^{34}$ Furthermore, inefficiencies in energy generation in many of these countries provide opportunities for low-cost reductions (Frankhauser and Lavric 2003).

Despite the large potential for reductions in many transition economies, there may be substantial disincentives for other Annex 1 nations to invest in these projects. Frankhauser and Lavric (2003) identify three elements as key determinants affecting JI investment in transition economies:

1. the scope for cheap reductions (in other words, the marginal abatement costs);

2. the institutional capacity of host countries, including experience gained during AIJ; and

3. the general business environment. This includes political and economic stability, progress in privatization, liberalization and structural reforms, quality of the legal system, and prevalence of corruption.

JI investors are most likely to be interested in countries with low marginal abatement costs, but high institutional capacity and a good business environment. However, there are important

\footnotetext{
${ }^{33}$ Korppoo and Moe (2008), page 306.

${ }^{34}$ Korppoo and Moe (2008), page 308.
} 
trade-offs. Frankhauser and Lavric (2003) found that the countries with the highest scope for cheap reductions also have the lowest institutional capacity and the worst business environment.

There is significantly less empirical evidence available about the environmental quality and cost impacts of JI than CDM. These issues are likely to be similar to those discussed in the CDM section above. Additionally, the question of the impact on the likelihood of commitments by developing nations is less relevant for JI, since the host countries under this program have already made some level of commitment under Kyoto.

\section{The Potential for Scaling Up Offset Programs}

A critical issue is whether offset programs, such as those reviewed here, can be scaled up. In this section we briefly review the literature on the potential for offset programs to be enlarged. Then, we consider suggestions for improving the design of existing offset programs generally. Lastly, we consider the unique challenges facing the larger-scale deployment of land use, land use change, and forestry projects as part of an international offset program.

\section{A. The Potential of Offset Programs}

There have been several attempts to model the impact of using various forms of economic instruments to reduce greenhouse gas emissions. In general, it is well-known that economic instruments can dramatically reduce the cost of achieving a given level of emission reductions. For example, the emission trading and offset provisions of the Kyoto Protocol could reduce compliance costs by 50\% in the first commitment period. ${ }^{35}$ However, cost savings estimates do not generally incorporate numerous market imperfections inherent in existing offset programs (such as transaction costs). In the case of offsets, the actual savings will depend critically on system design, and assumptions about leakage and transaction costs. If we assume that offsets can be designed in a way to mimic the impact of well-run economic incentive schemes, then the savings could be quite large. Of course, this is probably an unrealistic assumption.

${ }^{35}$ Cited in Frankauser and Lavric (2003), page 418. 
Moreover, most simulations of offset potentials focus on the role of LULUCF projects. In these models, land use projects generally appear to be attractive as a least-cost offset options over the short term (30 years). These offsets are primarily generated via five avenues (Schlamadinger et al. 2007): 1) provision of renewable energy, 2) substitution for fossil carbonintensive products, 3) reduction in emissions of non- $\mathrm{CO}_{2}$ GHGs (from agriculture), 4) sequestration through enhanced terrestrial carbon stocks and 5) conservation of existing terrestrial carbon stocks. Models ${ }^{36}$ suggest that at low carbon prices $\left(\$ 5 / \mathrm{t} \mathrm{CO}_{2}\right)$, there is a great deal of tillage modification in agricultural soils, which is cheap, but does not provide much reduction. As $\mathrm{CO}_{2}$ prices increase, afforestation projects become more attractive. They have higher reductions, but also require conversion of land from agriculture. Finally, at prices higher than $\$ 15 / \mathrm{CO}_{2}$, longer-term projects such as biofuel production are induced. More capitalintensive (non-LULUCF) options provide the bulk of mitigation in the long run, but are limited in the short term by the relatively slow rate of capital stock turnover and other factors (McCarl and Sands 2007).

Additional studies support the finding that land use projects may be the lowest-cost offset options, at least in the short term. Estimates from the literature for the costs of mitigation via reforestation, afforestation, and forest management vary; one shows costs as low as \$5 per tonne $\mathrm{CO}_{2}$-equivalent in the United States, ${ }^{37}$ while another shows a range of \$0.1 to \$20 per tonne of carbon in tropical countries, and up to $\$ 100$ per tonne in non-tropical countries. ${ }^{38}$ In the area of agriculture, Richards et al. (2006) found that modification of agricultural practices on current farmlands could sequester 70 million metric tons of carbon at a cost of about $\$ 12.50$ per tonne of $\mathrm{CO}_{2}{ }^{39}$

\footnotetext{
${ }^{36}$ McCarl and Sands (2007), pages 122-123; EPA (2005), page ES-2.

${ }^{37}$ EPA (2009), page ES-2.

${ }^{38}$ IPCC (2001), page 8. Note that these cost figures are reported in dollars per tonne carbon rather than the more common metric, dollars per tonne $\mathrm{CO}_{2}$. Converted to $\$ / t \mathrm{CO}_{2}$, these cost figures are approximately $\$ 0-\$ 5.60 / t \mathrm{CO}_{2}$ for tropical countries and up to $\$ 28 / \mathrm{t} \mathrm{CO}_{2}$ in non-tropical countries.

39 These figures are specific to the United States and thus do not translate directly to international offset programs. However, they do provide some insight into how large the potential for terrestrial sinks are both domestically and abroad.
} 
On a global scale, Tavoni et al. (2007) modeled a theoretical atmospheric concentration goal of $550 \mathrm{ppmv} \mathrm{CO}_{2}$ (an intermediate stabilization target listed by the IPCC). They found that forestry sinks could contribute one third of total abatement by 2050 and decrease the price of carbon by $40 \%$. Total costs of the forestry program would be $\$ 1.1$ trillion and benefits (versus using different technology to achieve the same abatement) would be $\$ 3$ trillion. ${ }^{40}$

These examples show that the potential for cost savings using LULUCF project offsets could be very large. However, the wide range of cost estimates highlights the heterogeneity of estimation methodologies and assumptions across the literature (Richards and Stokes 2004). Additionally, the literature to date largely ignores the secondary benefits of land use projects, such as the conversion of land from agriculture to forestry, and these benefits may actually exceed the costs—making these projects "no regrets” (Richards and Stokes 2004).

Further, since the large-scale deployment of LULUCF projects is currently heavily curtailed under existing offset frameworks, modeling should focus more clearly on the technologies and projects that are allowable under realistic international agreements such as CDM and JI. Because the available evidence suggests that there may be substantial hurdles to the effective deployment of large-scale offset programs, there is also a need for more realistic modeling. This modeling could include transaction costs, administrative costs, a realistic assessment of additionality, and leakage.

\section{B. Suggestions for Improving the Design of Current Offset Programs}

Several evaluations of the current project-based mechanisms have generated suggestions for how these programs can be improved. For example, UNFCCC's Seventh Synthesis Report on AIJ activities (2006) offered several lessons learned about projects in transition economies (i.e. JI projects). These include a need for: a) closer cooperation between national and local authorities, b) engagement of local experts, c) training and outreach in local languages, d) packaging technology transfer and capacity building, e) follow-up and feedback, and f) longterm commitment from both parties.

\footnotetext{
${ }^{40}$ Net Present Value to 2100. Tavoni et al. (2007), page 5353.
} 
Some authors have suggested major revisions to the frameworks of the current offset mechanisms, arguing that these overhauls will enhance environmental quality while also improving the cost-effectiveness of implementation. Hepburn (2007) and Wara (2007) suggest that the $\mathrm{CDM}$ market should be restricted to $\mathrm{CO}_{2}$ reduction projects to discourage disproportionate emphasis on relatively cost-ineffective, non- $\mathrm{CO}_{2}$ projects such as $\mathrm{HFC}-23$ capture. Wara (2007) suggests that a separate agreement for this greenhouse gas, isolated from the market for $\mathrm{CO}_{2}$ reductions, would save approximately $€ 4.6$ billion in CDM credits. The prices paid for the resultant credits would likely reflect the marginal cost of reduction rather than the inflated prices associated with $\mathrm{CO}_{2}$-equivalent CERs of the CDM market. ${ }^{41}$ Both Hepburn and Wara argue that differentiating the markets for different greenhouse gases would help direct CDM investments to targeted sectors such as renewable energy infrastructure rather than non$\mathrm{CO}_{2}$ projects such as HFC-23 capture. The authors argue that this is an important priority, given that many developing nations are currently locking in carbon-intensive energy capital.

Other authors have made suggestions that directly pertain to specific concerns that dominate the offsets literature, including environmental quality impacts, and transaction and administrative cost impacts. The following sections provide overviews of suggestions in each of these two areas.

\section{i. Improving Environmental Quality Outcomes}

Empirical evidence to date from three operational international project-based programs suggests that large scale offset programs may undermine the environmental quality goals of the Kyoto Protocol, mainly due to the questionable additionality of credit-generating projects. Currently, a CDM project is considered additional if "anthropogenic GHG emissions are reduced below those that would have occurred in the absence of the registered CDM project activity.” In order for offset programs to be successful, there is need for firm additionality measurement criteria to ensure that we are not subsidizing already-viable business activities, and thereby compromising environmental integrity (Greiner and Michaelowa 2003). Wara and Victor (2008)

\footnotetext{
${ }^{41}$ Wara (2007), page 596.
} 
are not optimistic that problems with additionality in the CDM market can be overcome, stating that it is possible to reward bona fide emissions in only a fraction of real-world offset markets, and that the theoretical benefits of low-cost reductions through international engagement are really an illusion.

Project developers currently use a variety of approaches for demonstrating additionality, which are discussed and evaluated by Schneider (2009). These include:

1. Positive lists, in which an entire project category is assumed to be additional. So far, this has only been applied to HFC-23 removal projects, as discussed in Section 2 of this report.

2. Barrier analysis, in which project developers demonstrated that barriers exist that would prevent project deployment in the absence of CDM credits. This approach is used by $74 \%$ of projects, but many of them do not provide sufficient evidence that the project would actually have been prevented-43\% don't even attempt to provide an explanation. Most of them cite costs as a barrier, but do not reveal what costs are. The information used for barrier analyses are usually highly subjective, vague, and difficult to validate.

3. Investment analysis, in which project developers show that the proposed project is economically or financially less attractive than at least one other alternative project (in the absence of CDM credits). This approach is used by approximately one third of projects. However, less than half of them provide sufficient information on the relevant cost and revenue streams, and 30\% provide no information. Also, there is no consistent benchmark for the hurdle rate or internal rate of return needed to justify deployment. In several cases, the CERs generated by CDM participation increase the IRR only minimally, not to the necessary level, but projects are concluded to be additional anyway.

4. Common practice analysis, in which project developers assess the degree to which the proposed project type has been deployed in the relevant sector or region, and show that the project or practice generating credits is the first of its kind. However, there is 
currently a lack of common benchmarks for what is unique and what is common practice.

As Schneider's evaluation demonstrates, the current procedures for ensuring additionality have largely been unsuccessful. This lends support to Wara and Victor's assessment that the hurdles to the demonstration and validation of additionality may prove insurmountable. However, Schneider also offers several alterations to current procedures that could improve the methods for demonstrating additionality.

- Avoid concentrating on the motives of the project developers (as this is highly subjective and difficult to verify), and instead focus on the market environment and current practices in the relevant region or sector.

- Exclude subjective and company-specific barriers when using barrier analysis.

- Specify particular requirements for first-of-its kind barriers, when possible.

- Make investment analysis (rather than barrier analysis) mandatory for large-scale investments, since other types of barriers are not credible, or can often be counted as costs in the analysis.

- Where possible, introduce quantitative thresholds for common practice analysis and require that other CDM projects are also included in the analysis.

- Exclude projects on which CDM credits have only a negligible impact on investment outcome (since these realistically will not impact investor decision).

Other authors also have recommendations for how additionality testing can be improved to address the environmental quality concerns with offset programs. For example, the current project-by-project approval process leads to inconsistent results, since project developers use different baselines over the same sectors and regions, with no incentive for cooperation (Lecocq and Ambrosi 2007). Instead of having project developers hire third party verifiers, the cost should be included in the project registration fee. That way, the CDM Executive Board can hire the verifiers, giving them an incentive to disclose as much information as possible (Wara 2008). Standardized accounting procedures could further constrain creative accounting practices on the part of project developers to overstate additionality. 
From another perspective, Wara (2008) suggests that unilateral actions could help to curtail environmental quality compromises where program design has failed. To increase the credibility of additionality claims, nations with potentially large shares of market control such as the United States could implement additional, more rigorous evaluation procedures before CERs could be traded domestically. This could lead to market fragmentation (with different CER prices in different countries). However, since the United States would likely have a very large share of the market, this could influence the entire market and motivate higher quality reductions from project developers everywhere (Wara 2008).

There are also important issues concerning offsets related to indirect effects. For example, the accounting framework used under Kyoto currently ignores emissions from burning biofuels, and it also ignores the land clearing involved in generating the fuels. This creates an incentive to increase land clearing as carbon caps get increasingly strict, leading to emission increases. In one modeled scenario, this oversight led to an additional $9 \mathrm{Gt} \mathrm{CO}_{2}$ emissions per year through 2050. ${ }^{42}$ Such accounting errors can be addressed through a more careful tracking of all emissions from biofuels, so that only actual net reductions from the use of biofuels are granted credits (Searchinger et al. 2009).

\section{ii. Minimizing Administrative and Transaction Costs}

As we place more emphasis on demonstrating additionality, the considerable administrative and transaction costs could increase substantially (Greiner and Michaelowa 2003; Andersson et al. 2009). However, there are also several proposals for how they can be reduced. For example, the use of brokers to facilitate trades could reduce the transaction costs associated with interactions between partners, while standardized approval and baseline establishment processes can reduce the cost of government interactions (Fichtner et al. 2003).

Additionally, the choice of partners (between investor and host nations) can have important impacts on the cost outcomes. Climate cooperation between countries requires reliability and longevity from the host country, making many potential host countries unsuitable

\footnotetext{
${ }^{42}$ Cited in Searchinger et al. (2009), page 528.
} 
(Dutschke 2000). In many countries, the capacity and resources to implement CDM programs is very limited, which may provide substantial barriers to deployment (Ellis et al. 2007). Existing ties between investor and host countries help to overcome the substantial transaction costs associated with bilateral projects (Larson and Breustedt 2009).

A criticism of CDM that is related to its administrative cost is its relative unpredictability and inconsistency, as discussed by Streck and Lin (2008 - see discussion in Section 2). The CDM mechanism can only be effective in the future if project participants can expect their actions to be rewarded appropriately with CERs. But currently, there is a lack of transparency and predictability. Incorporating new mechanisms such as an appeals process into the Executive Board review could promote procedural fairness, transparency, and accountability (Streck and Lin 2008).

\section{Incorporating Land Use, Land Use Change, and Forestry}

Although a large body of literature suggests that LULUCF projects can contribute a significant share of mitigation at low costs, they also have a unique set of problems that so far have limited large-scale deployment under existing mechanisms. CDM does not currently allow forest conservation to generate CERs, at least in part due to concerns about additionality and leakage. Instead, the Kyoto Protocol allows only reforestation and afforestation projects to count for offsets under CDM, and they are limited to satisfying 1\% of a nation's base year (1990) emissions per year during the first commitment period.

One problem with the large-scale deployment of land-based projects is saturation; there is a limit to the amount of carbon that can be sequestered by biological systems (Schlamadinger et al. 2007). Eventually, the terrestrial biosphere will reach a steady state or carbon equilibrium in which it will not uptake additional carbon (Schlamadinger et al. 2007; Kim et al. 2008). For example, agricultural soil sequestration options have 20 years of potential reductions from reduced tillage, and then an additional 50 years in land use change (McCarl and Sands 2007). Forests also have diminishing rates of carbon uptake until they reach equilibrium, which is at about 80 years for some forest types (McCarl and Sands 2007). 
Imprecision of measurement is also a serious issue for these projects. The error bounds associated with measuring and monitoring forest carbon are very large, even in developed nations with good technology. They are likely to be substantially wider in developing nations (Tavoni et al. 2007).

One of the most serious problems associated with land use offsets is reversal or impermanence. This is the intentional or unintentional release of stored carbon back into the atmosphere due to a) severity, duration, and frequency of natural disturbances, b) the response of trees to increased atmospheric $\mathrm{CO}_{2}$ and climate change, or c) landowner behavior (Galik and Jackson 2009). Eventually, stored carbon will be re-released back into the atmosphere. Thus, there is concern that generation of credits via LULUCF will facilitate increased emissions in the long run (Kim et al. 2009). Currently, the non-permanence of land-based projects is accounted for in CDM with the use of temporary credits. The Annex 1 country using the credits generated by LULUCF projects have to replace the credits when the carbon is released into atmosphere, or after 5 years (Schlamadinger et al. 2007). They also have to be re-verified periodically to be comparable to more permanent forms of reductions, which makes them less valuable in the carbon market (Kim et al. 2009).

Land use projects are also uniquely situated in the natural environment, making the differentiation of impacts from human activities and natural occurrences complex (Gillespie 2003; Schlamadinger et al. 2007). For example the growth rate of trees relies on many natural factors such as rainfall and temperature. The interaction of man-made changes and natural factors can make it difficult to determine the sequestration that is attributable to human efforts. Essentially, this is a baseline issue-how many credits should be awarded to projects that occur on land that was likely to generate some level of sequestration anyway?

A final challenging issue pertaining to the widespread deployment of land use and forestry projects is leakage. This is not unique to LULUCF projects, but it is a substantially bigger problem here than it is for many other sectors. If leakage is significant, then the government could spend billions with no real net gain in carbon stocks (Richards and Stokes 
2004). Estimates for the scale of leakage range widely from $10 \%$ of mitigation being compromised up to 90\% (Murray et al. 2004). Murray et al. (2004) evaluated likely leakage rates for a variety of land use activities. For forest preservation, the predicted leakage level is 87\%, which is consistent with empirical evidence from North America. ${ }^{43}$ For forest set-asides (which permanently remove private forests from harvest), leakage ranges $16-68 \% .{ }^{44}$

Some authors have proposed ways to address these problems so that low-cost land use offsets may be used more extensively as a bridge to other more permanent, capital-intensive mitigation projects later. Schlamadinger et al. (2007) suggest using separate targets for separate sectors. For example sequestration using LULUCF would not count against increased emissions in other sectors, such as energy. Schwarze et al. (2002) discuss several potential tools for reducing leakage from offset programs incorporating LULUCF projects:

- Site selection: seek out areas for reforestation/afforestation that do not have many competing uses.

- Leakage contract: logging concessionaires sign contracts agreeing not to use CER revenues to pursue logging elsewhere

- Discounting: establish discount rates based on modeling to account for leakage.

- Limit the scope of LUCF projects that can satisfy requirements.

Sun and Sohngen (2009) and Galik and Jackson (2009) discuss ways to combat reversal and address impermanence. Table 5 shows the options discussed by Galik and Jackson (2009), which include liability assignment, mandatory insurance policies, buffer zones, and improved forest management policies. Sun and Sohngen (2009) examine a more specific approach-the use of forest set-asides--in which land areas are permanently removed from timber production. According to the authors, set-asides could address the permanence issue and achieve 106-128 billion tonnes of carbon sequestration by 2105 , at costs up to $\$ 187 /$ tonne carbon. ${ }^{45}$ However, the risk of leakage associated with set-asides is large. A policy in which set asides complement

\footnotetext{
${ }^{43}$ Murray et al. (2004), page 118.

${ }^{44}$ Murray et al. (2004), page 119.

${ }^{45}$ Sun and Sohngen (2009), page 416-417. This equates to approximately $\$ 52 / \mathrm{t} \mathrm{CO}_{2}$.
} 
other LULUCF activities achieves much larger reductions and has less leakage than one that relies on set-asides exclusively.

\section{Conclusion}

This review of AIJ, CDM, JI and related programs leads us to the following conclusions:

- Offset projects may reduce environmental quality because of problems with additionality and leakage.

- Offset projects may help contribute to environmental quality by making a deal on climate change more attractive to some countries interested in setting binding targets.

- Offsets are probably best understood in terms of a political compromise regarding market-based approaches (where there is a wish to lower costs without having a large impact on environmental quality).

- The design and success of offsets will depend on the scientific, technical, political and legal environment in which they are implemented.

- The design of offsets will typically involve a tradeoff between cost savings and environmental quality.

- Offsets may have some potential, but are not likely to be a panacea. There are likely to be significant challenges in scaling up offset programs.

We also believe that more research is needed on the effectiveness of offset programs. There is a need to understand trade-offs in system design better, including, but not limited to, trade-offs between cost savings and environmental quality. The impact of different offset 
program designs on additionality and leakage should be part of that research. Finally, there is a need to model the potential for offsets using policies that reflect actual design constraints. ${ }^{46}$

We believe that offsets will probably continue to play a role in future carbon mitigation strategies. Given their potential for reducing environmental quality and their relatively high administrative and transaction costs, offsets are not a panacea. However, evidence suggests that they have potential to lower the costs associated with carbon mitigation and that there may be some constructive ways to deal with the environmental quality issues without negating cost savings.

${ }^{46}$ There is an interesting methodological question that needs to be addressed with respect to the use of offsets and an appropriate counterfactual. One counterfactual is what would have happened under "business-as-usual”, assuming a binding regulatory agreement was already in place for selected countries (e.g., Annex 1 countries in the case of Kyoto). However, what if a particular offset program was a condition for a country entering into an agreement with a binding target? This would suggest a different baseline against which to measure the effectiveness of an offset program. In practice, this baseline may be much more difficult to specify. 


\section{References}

Andersson, K., T.P. Evans, and K.R. Richards. 2009. National Forest Carbon Inventories: Policy and Assessment Capacity. Climatic Change 93: 69-101.

Barrera, J. and R. Schwarze. 2004. Does the CDM Contribute to Sustainable Development? Evidence from the AIJ Pilot Phase. International Journal of Sustainable Development 7: 353368.

Chadwick, B.P. 2006. Transaction Costs and the Clean Development Mechanism. Natural Resources Forum 30: 256-271.

Chomitz, K.M. 2000. Evaluating Carbon Offsets from Forestry and Energy Projects: How do they Compare? World Bank Development Research Group. Policy Research Working Paper 2357.

de Sepibus, J. 2008. Linking the EU Emissions Trading Scheme to JI, CDM, and post-2012 International Offsets: A Legal Analysis and Critique of the EU ETS and the Proposals for its Third Trading Period. NCCR Working Paper 2008/18.

Dolsak, N. and M. Dunn. 2006. Investment in Global Warming Mitigation: The Case of “Activities Implemented Jointly.” Policy Science 39: 233-248.

Dutschke, M. 2000. Host Country Driven Implementation--The Case of Costa Rica. Climate Policy and Development: Flexible Instruments and Developing Countries. A. Michaelowa and M. Dutschke (eds.)

Ellis, J., H. Winkler, J. Corfee-Morlot, and F. Gagnon-Lebrun. 2007. CDM: Taking Stock and Looking Forward. Energy Policy 2007: 15-28.

Environmental Protection Agency (EPA). 2005. Greenhouse Gas Mitigation Potential in U.S. Forestry and Agriculture.

Fichtner, W., S. Graehl, and O. Rentz. 2003. The Impact of Private Investor's Transaction Costs on the Cost Effectiveness of Project-Based Kyoto Mechanisms. Climate Policy 3: 249-259.

Figueres, C. 2006. Sectoral CDM: Opening the CDM to the Yet Unrealized Goal of Sustainable Development. International Journal of Sustainable Development Law and Policy 6: 5-25.

Frankhauser, S. and L. Lavric. 2003. The Investment Climate for Climate Investment: Joint Implementation in Transition Countries. Climate Policy 3: 417-434.

Galik, C.S. and R.B. Jackson. 2009. Risks to Forest Carbon Offset Projects in a Changing Climate. Forest Ecology and Management 257: 2209-2216. 
Gillespie, A. 2003. Sinks and the Climate Change Regime: The State of Play. Duke Environmental Law and Policy 13.

Greiner, S. and A. Michaelowa. 2003. Defining Investment Additionality for CDM ProjectsPractical Approaches. Energy Policy 31: 1007-1015.

Gupta, J., P. van Beukering, H. van Asselt, L. Brander, S. Hess, and K. van der Leeuw. 2008. Flexibility Mechanisms and Sustainable Development: Lessons from Five AIJ Projects. Climate Policy 8: 261-276.

Hahn, R.W. and G.L. Hester. 1989. Marketable Permits: Lessons for Theory and Practice. Ecology Law Quarterly 16: 361-406.

Hepburn, C. 2007. Carbon Trading: A Review of the Kyoto Mechanisms. Annual Review of Environment and Resources 32: 375-393.

Intergovernmental Panel on Climate Change (IPCC). 2001. Climate Change 2001: Mitigation. Summary for Policymakers. Report of Working Group III.

Jotzo, F. and A. Michaelowa. 2002. Estimating the CDM Market under the Marrakech Accords. Paper for the $3{ }^{\text {rd }}$ CATEP workshop "Global Trading”, Kiel Institute for World Economics.

Kallbekken, S., L.S. Flottorp, and N. Rive. 2007. CDM Baseline Approaches and Carbon Leakage. Energy Policy 35: 4153-4163.

Kim, M.K., B.A. McCarl, and B.C. Murray. 2008. Permanence Discounting for Land-Based Carbon Sequestration. Ecological Economics 64: 763-769.

Korppoo, A. and A. Moe. 2008. Joint Implementation in Ukraine: National Benefits and Implications for Further Climate Pacts. Climate Policy 8: 305-316.

Krey, M. 2005. Transaction costs of Unilateral CDM Projects in India-Results from an Empirical Survey. Energy Policy 33:2385-2397.

Larson, D.F. and G. Breustedt. 2009. Will Markets direct investments under the Kyoto Protocol? Lessons from the Activities Implemented Jointly pilots. Environment and Resource Economics 43: 433-456.

Lecocq, F. and P. Ambrosi. 2007. The Clean Development Mechanism: History, Status, and Prospects. The Review of Environmental Economics and Policy 1: 134-151.

Mattoo, A., A. Subramanian, D. van der Mensbrugghe, and J. He. 2009. Reconciling Climate Change and Trade Policy. Peterson Institute for International Economics Working Paper 09-15.

McCarl, B.A. and R.D. Sands. 2007. Competitiveness of Terrestrial Greenhouse Gas Offsets: Are They a Bridge to the Future? Climatic Change 80: 109-126. 
Michaelowa, A. 2002. The AIJ Pilot Phase as Laboratory for CMD and JI. The International Journal of Global Environmental Issues 2: 260-287.

Michaelowa, A. and F. Jotzo. 2003. Impacts of transaction costs and institutional rigidities on the share of the Clean Development Mechanism in the global greenhouse gas market.

Michaelowa, A. and F. Jotzo. 2005. Transaction costs, Institutional Rigidities, and the Size of the Clean Development Mechanism. Energy Policy 33: 511-523.

Michaelowa, A. and P. Purohit. 2007. Additionality determination of Indian CDM projects: Can Indian CDM project developers outwit the CDM Executive Board? University of Zurich, Institute for Political Science.

Murray, B.C., B.A. McCarl, and H.C. Lee. 2004. Estimating Leakage from Forest Carbon Sequestration Programs. Land Economics 80: 109-124.

Murray, B.C, B. Sohngen, and M.T. Ross. 2007. Economic consequences of consideration of permanence, leakage, and additionality for soil carbon sequestration projects. Climatic Change 80: $127-143$.

Nussbaumer, P. 2009. On the contribution of labeled Certified Emission Reductions to sustainable development: A multi-criteria evaluation of CDM projects. Energy Policy 37: 91101.

Richards, K.R. and C. Stokes. 2004. A Review of Forest Carbon Sequestration Cost Studies: A Dozen Years of Research. Climatic Change 63: 1-48.

Richards, K.R., R.N. Sampson, and S. Brown. 2006. Agricultural and Forestlands: U.S. Carbon Policy Strategies. Pew Center on Global Climate Change.

Schlamadinger, B., et al. 2007. A Synopsis of Land Use, Land Use Change, and Forestry (LULUCF) under the Kyoto Protocol and Marrakech Accords. Environmental Science and Policy 10: 271-282.

Schneider, L. 2009. Assessing the Additionality of CDM Projects: Practical Experiences and Lessons Learned. Climate Policy 9: 242-254.

Schwarze, R., J.O. Niles, and J. Olander. 2002. Understanding and Managing Leakage in Forest-Based Greenhouse-Gas-Mitigation Projects. Philosophical Transactions: Mathematical, Physical, and Engineering Sciences 360: 1685-1703.

Searchinger, T.D. et al. 2009. Fixing a Critical Climate Accounting Error. Science 326: 527528. 
Streck, C. and J. Lin. 2008. Making Markets Work: A Review of CDM Performance and the Need for Reform. The European Journal of International Law 19.

Sun, B. and B. Sohngen. 2009. Set-Asides for Carbon Sequestration: Implications for Permanence and Leakage. Climatic Change 96: 409-419.

Sutter, C. and J.C. Parreno. 2007. Does the Current Clean Development Mechanism (CDM) Deliver its Sustainable Development Claims? An Analysis of Officially Registered CDM Projects. Climatic Change 84: 75-90.

Tavoni, M., B. Sohngen, and V. Bosetti. 2007. Forestry and the Carbon Market Response to Stabilize Climate. Energy Policy 35: 5346-5353.

UNFCCC. 2006. Activities Implemented Jointly under the Pilot Phase: Seventh Synthesis Report. FCCC/SBSTA/2006/8.

UNFCCC. 2009. www.cdm.unfcc.int/index.html

Wara, M.W. 2007. Is the Global Carbon Market Working? Nature Commentary 445: 595-596.

Wara, M.W. 2008. Measuring the Clean Development Mechanism’s Performance and Potential. Program on Energy and Sustainable Development, Working Paper \#56.

Wara, M.W. and D.G. Victor. 2008. A Realistic Policy on International Carbon Offsets. Program on Energy and Sustainable Development, Working Paper \#74. 
Figure 1

\section{CDM Volume by Project Type}

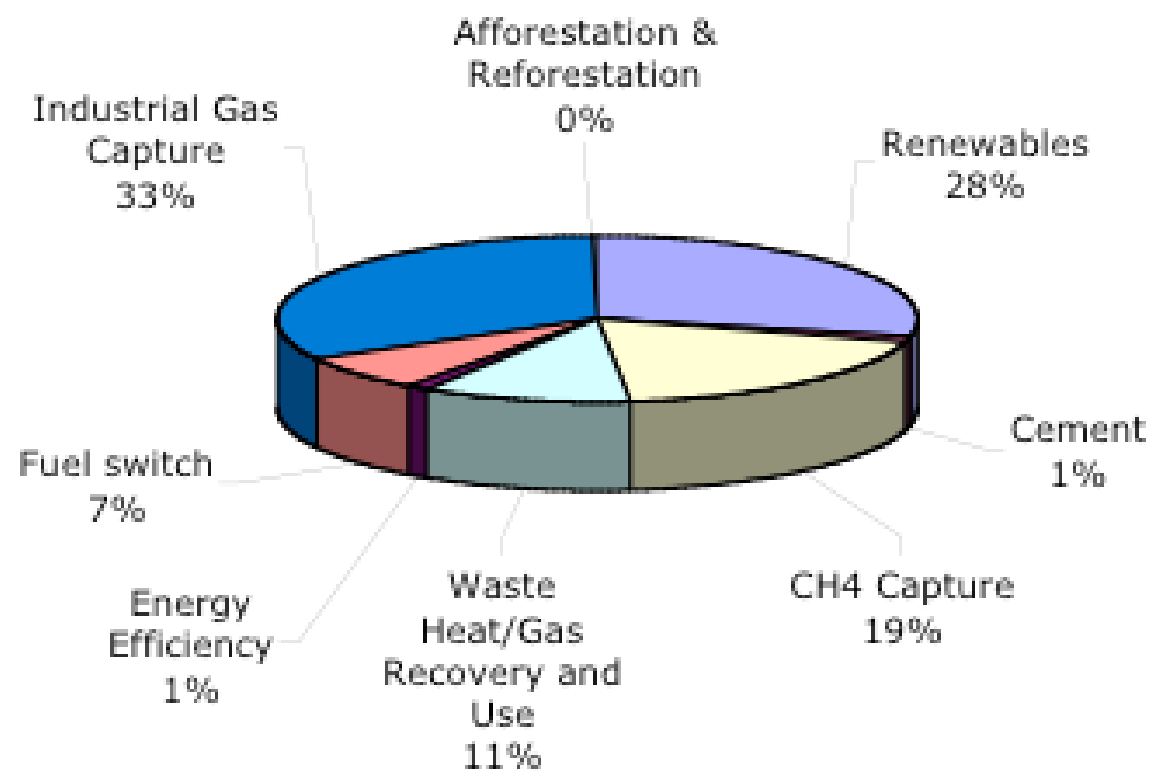

Fraction of CERs supplied to 2012 by different project types for all projects currently in the CDM pipeline

Source: (Wara 2008; page 23). 


\section{Table 1}

\section{Economies of scale in AIJ project transaction costs $\left(€ / t \mathrm{CO}_{2}\right)$}

\begin{tabular}{|l|c|c|c|}
\hline \multicolumn{1}{|c|}{ Size ( $\mathrm{CO}_{2}$ /year) } & $\begin{array}{c}\text { Energy efficiency (number of } \\
\text { projects) }\end{array}$ & $\begin{array}{c}\text { Renewable energy (number of } \\
\text { projects) }\end{array}$ & \begin{tabular}{c} 
Mixed (number of projects) \\
\hline$>10,000$
\end{tabular}$-^{1.3-1.8(5)}$ \\
\hline $5000-10,000$ & - & $1.7-3.1(8)$ & $1.4(1)$ \\
\hline $2500-5000$ & $2.7(1)$ & $2.7-5.6(5)$ & $4.6(1)$ \\
\hline $1000-2500$ & $3.0-9.7(6)$ & $5.1-11.1(8)$ & $11.7(1)$ \\
\hline $500-1000$ & $17.8-40.4(3)$ & - & $16.2(1)$ \\
\hline $100-500$ & $29.1-61.2(9)$ & - & \\
\hline$<100$ & $80.8-123.9(2)$ & - & \\
\hline
\end{tabular}

Source: (Michaelowa and Jotzo 2003; page 6). 
Table 2

Cost groups and cost components of unilateral CDM projects

\begin{tabular}{ll}
\hline Cost group & Cost components \\
\hline Market transaction costs & Search costs \\
& Negotiation costs \\
Pre-implementation transaction costs & PDD costs \\
& Approval costs \\
& Validation costs \\
& Registration costs \\
& Monitoring costs \\
Implementation transaction costs & Verification \& certification \\
& (V\&C) costs \\
& Costs of the adaptation fee \\
\hline
\end{tabular}

Source: (Krey 2005; page 2388). 


\section{Table 3}

\section{Definition of CDM transaction costs components}

\begin{tabular}{|c|c|c|c|}
\hline $\begin{array}{l}\text { Transaction Cost Compo- } \\
\text { nents }\end{array}$ & $\begin{array}{l}\text { Costs incurred by investors and hosts as they seek out } \\
\text { partners for mutually advantageous projects }\end{array}$ & $\begin{array}{l}\text { Relation to proj- } \\
\text { ect size }\end{array}$ & $\begin{array}{c}\text { Estimate } \\
\text { (k€) }\end{array}$ \\
\hline Search costs & & fixed & 15 \\
\hline Negotiation costs & $\begin{array}{l}\text { Includes those costs incurred in the preparation of the } \\
\text { project design document that also documents assignment } \\
\text { and scheduling of benefits over the project time period. It } \\
\text { also includes public consultation with key stakeholders }\end{array}$ & degressive & $25-400$ \\
\hline Project documentation costs & Development of a baseline and monitoring plan & fixed & 35 \\
\hline Approval costs & Costs of authorisation from host country & proportional & $40^{*}$ \\
\hline Validation costs & $\begin{array}{l}\text { Review and revision of project design document by opera- } \\
\text { tional entity }\end{array}$ & fixed & $15-30$ \\
\hline Registration costs & Registration by CDM Executive Board & $\begin{array}{l}\text { Slightly degres- } \\
\text { sive }\end{array}$ & 10 \\
\hline Monitoring costs & Costs to collect data & fixed & 10 \\
\hline Verification costs & $\begin{array}{l}\text { Cost to hire an operational entity and to report to the CDM } \\
\qquad \text { Executive Board }\end{array}$ & degressive & $\begin{array}{l}8 \text { per } \\
\text { turn }\end{array}$ \\
\hline Certification costs & Issuance of CERs by UNFCCC Executive Board & degressive & NA \\
\hline Enforcement costs & $\begin{array}{l}\text { Includes costs of administrative and legal measures in- } \\
\text { curred in the event of departure from the agreed transac- } \\
\text { tion }\end{array}$ & proportional & \\
\hline Transfer costs & Brokerage costs & proportional & $1 \%$ \\
\hline Registry costs & Costs to hold an account in national re gistry & proportional & $003 \%$ \\
\hline Minimum fixed cost $(k \Theta)$ & & & 150 \\
\hline
\end{tabular}

Sources: Cost estimates from the case studies below and SGS (2002); the registry cost is derived from costs of share deposits at online brokerages

Source: (Michaelowa and Jotzo 2003; page 4). 


\section{Table 4}

\section{Range of transaction costs of Indian case study of CDM projects}

\begin{tabular}{|c|c|c|}
\hline \multirow[t]{2}{*}{ Trunsactioe costs ${ }^{2}$} & \multicolumn{2}{|l|}{ Range } \\
\hline & Absolute (SUS) & Specific ( $\left(\mathrm{SUS} / \mathrm{t} \mathrm{CO}_{2}\right)$ \\
\hline Costs for finding a buycr $(9)^{\mathrm{b}}$ & $19,000-29,000$ & $0.005-0.091$ \\
\hline Negotiation costs (7) & 10,500 & $0.002-0.044$ \\
\hline PDD costs $(14)$ & $6,500-120,000$ & $0.004-0.125$ \\
\hline Approval costs (0) & - & - \\
\hline Vatidation costs ( 3 ) & $6,000-80,000$ & $0.003-0.000$ \\
\hline Registration costs (15) & $5,000-30,000$ & $0.006-0.042$ \\
\hline Monitoring costs (0) & - & - \\
\hline$V+C \operatorname{costs}(0)$ & - & - \\
\hline Adaptation foe (12) & $10,193-212,349$ & 0.0420 .008 \\
\hline Total $(0)$ & - & - \\
\hline Sum survey & $57,193-481,849$ & 0.0620 .470 \\
\hline
\end{tabular}

"Only those projects for which all sub-cost components, if applicable, of the respective cost component could be quantified are considered in this table.

'The number in beackets shows for how many projects the respective cost component could be quantified.

Source: (Krey 2005; page 2391). 


\section{Table 5}

\section{Mechanisms and strategies to address reversal risk in forest offset projects}

\begin{tabular}{|c|c|c|c|}
\hline Mechanism/strategy & Overview & $\begin{array}{l}\text { Scope of } \\
\text { coverage }\end{array}$ & Implemencation eximples \\
\hline Forest Management & Management of forests to promote resistance to or resilience from disturbance. & Project & $\begin{array}{l}\text { Califorma Climate Action Registry }(2007\rangle \\
\text { and Voluntary Carbon Standard }(2007)\end{array}$ \\
\hline $\begin{array}{l}\text { Inclusion of Salvage? } \\
\text { Wood Products }\end{array}$ & $\begin{array}{l}\text { Minimizes impact of distubance on project by providing credit for carton } \\
\text { in desd/downed wood or storage in wood products. }\end{array}$ & Project & 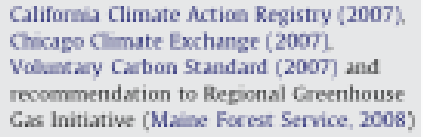 \\
\hline Assignment of liabaliry & $\begin{array}{l}\text { Infoence of behavior by identifying the party respoesilble for repaying last } \\
\text { carbon storage. }\end{array}$ & Project & $\begin{array}{l}\text { Califorma Climate Action Registry }(2007) \\
\text { Chocago Climate Exchange }(2007) \text { and } \\
\text { Voluancary Cabon Standand }(2007)\end{array}$ \\
\hline Insurance & Allows for the replacement of lost carbon in the event of reversal. & Project & $\begin{array}{l}\text { AIG Ine. (2007): Recommendabon to } \\
\text { segoonal Greenhouse Gas Initiative (Maine } \\
\text { forest Service, 2000) }\end{array}$ \\
\hline Buffer & $\begin{array}{l}\text { Sequires ses-aside of some portion of storage in project-specific of } \\
\text { program-wide pool. }\end{array}$ & $\begin{array}{l}\text { Project to } \\
\text { Program }\end{array}$ & $\begin{array}{l}\text { Cascago Cimate Exchange }(2007) \text { and } \\
\text { Voluanary Cathon Standard }(2007)\end{array}$ \\
\hline Portílio Diversification & $\begin{array}{l}\text { Minimizes impact of disturbances by pooling diverse project types or projects } \\
\text { in geographically diverse areas. }\end{array}$ & $\begin{array}{l}\text { Region to } \\
\text { Program }\end{array}$ & $\begin{array}{l}\text { Lauriksa and Springer }(2009) \text { and Hultman } \\
\text { (2006) }\end{array}$ \\
\hline Program re-evaluation & $\begin{array}{l}\text { Peniodic evaluation of expected sequestration versus realized. allowing for } \\
\text { additional credits to be relezised or withheld. }\end{array}$ & Program & Murray and Dlander (2008) \\
\hline
\end{tabular}

Source: (Galik and Jackson 2009; page 2214). 


\section{Appendix A: Annotated Bibliography}

This appendix provides an annotated bibliography for the carbon offset literature that has contributed to our analysis. The works cited primarily address the environmental quality and costs of the three project-based mechanisms that form the basis for our overall analysis: Activities Implemented Jointly (AIJ), Clean Development Mechanism (CDM), and Joint Implementation (JI).

Works are cited in alphabetical order, with the article's abstract or summary provided immediately after the citation.

Andersson, K., T.P. Evans, and K.R. Richards. 2009. National Forest Carbon Inventories: Policy and Assessment Capacity. Climatic Change 93: 69-101.

Abstract: Previous research has identified the importance of the role of land cover in the global carbon cycle. In particular, forests have been identified as a significant carbon sink that can mitigate the rate of global climate change. Policy makers are faced with complex and difficult challenges in getting timely and useful information in monitoring global forest resources. Recent advances in the tools and methods of forest carbon accounting have produced new, innovative approaches to forest- based carbon inventories. But it is important as new tools are developed that scientists understand the needs of policy makers and that policy makers understand the capabilities and limitations of forest inventory methods. This paper explores four different policy applications that rely, or could benefit from, national carbon inventories. The goal is to help build a bridge between the communities of climate policy makers and scientists specialized in forest carbon inventories. To this end, we pursue three specific objectives: First we provide an overview for policy makers about approaches to forest carbon inventories, paying particular attention to the contributions of remote sensing technologies. Second, we outline the issues particularly relevant to forest inventory scientists who are interested in responding to public policy needs. We then discuss the tradeoffs between information cost, accuracy, precision, transparency and timeliness that need to be balanced in long-term monitoring of forest carbon. 
Finally, the article concludes with a series of observations and recommendations for the implementation of forest carbon inventories as increasingly central components of global climate change policy.

Barrera, J. and R. Schwarze. 2004. Does the CDM Contribute to Sustainable Development? Evidence from the AIJ Pilot Phase. International Journal of Sustainable Development 7: 353-368.

\begin{abstract}
The purpose of the Activities Implemented Jointly (AIJ) program, adopted at the first Conference of the Parties to the United Nations Framework Convention on Climate Change, is the foster the transfer of technology for global warming abatement from developed to developing countries. Projects should not only reduce greenhouse gases, but also contribute to the sustainable development goals of host countries. However, given the lack of consensus regarding the definition and measurement of sustainable development, it is difficult to gauge to what extent the AIJ phase has been useful for developing countries. In this paper, we adopt a macro perspective and analyse the real-life data of 210 projects with respect to equity and financial issues related to sustainable development in a broad sense. We focus only on three aspects (financial additionality, credit sharing, and geographic distribution) and conclude that the performance of the AIJ program was in general fairly poor. Because the AIJ experience prepares the grounds and is fundamental for the design of two project-based mechanisms from the Kyoto Protocol (JI and CDM), these failures must be overcome and strong sustainable development criteria must be set for each project.
\end{abstract}

Chadwick, B.P. 2006. Transaction Costs and the Clean Development Mechanism. Natural Resources Forum 30: 256-271.

Abstract: The emissions trading provisions of the Kyoto Protocol and its clean development mechanism (CDM) are designed to permit greenhouse gas (GHG) emission reductions at the lowest cost globally. However, to ensure climate integrity, these reductions must pass through 
vigilant approval, monitoring and evaluation procedures that create additional transaction costs unrelated to the physical process of eliminating GHGs. Moreover, the CDM's additionality criterion creates constraints that magnify the influence of these transaction costs on project viability. If these costs are extreme, they could undermine the success of the CDM, and possibly of the Kyoto Protocol itself. This article describes the trading provisions of the treaty, creates a working definition of transaction costs, and discusses their effects. It then analyzes the process of creating a CDM project to identify the sources of transaction costs, illustrated by an example of a fuel substitution project in Ghana. The conditions for project profitability are analyzed and compared with recent GHG emission credit prices in Europe. The specific Ghanaian results are not generalizable to all CDM projects, but the model does suggest a template that can be used to analyze the effects of project and transaction costs in other contexts.

\section{Chomitz, K.M. 2000. Evaluating Carbon Offsets from Forestry and Energy Projects: How do they Compare? World Bank Development Research Group. Policy Research Working Paper 2357.}

\footnotetext{
Abstract: Do forestry projects, as a class, face more difficulties than energy projects in producing greenhouse gas emissions reductions that are real, measurable, additional and consistent with sustainable development? This paper considers the main criteria for qualifying a project that produces emissions reductions: baseline and additionality determination, leakage assessment, measurement of actual emissions or sequestration, and duration or permanence. For all the criteria except permanence, it is difficult to find generic distinctions between LUCF and energy projects, since each of these two categories comprises diverse project types. Instead, the important distinctions among projects have to do with such things as:

- The level and distribution of direct financial benefits that result from the project

- The degree to which the project is integrated with a broader physical and economic system

- The internal homogeneity and geographic dispersion of the project components

- The local replicability of project technologies

These dimensions cut across the energy vs. LUCF distinction.
} 
Permanence is an issue specific to LUCF projects. Several potential approaches are available to ensure permanence or adjust credits for duration. The ton-year approach focuses on the benefits from deferring climatic damage, and rewards longer deferral. The combination approach assures permanence by bundling current LUCF emissions reductions with future reductions in the buyer's allowed amount. A technology-acceleration approach taxes LUCF emissions reductions to fund accelerated research and development of emissions abatement technology. An insurance approach adjusts LUCF emissions reductions for the risk of premature release, spreads the risk across a world portfolio of projects, and supports institutions that minimize the risk.

\title{
de Sepibus, J. 2008. Linking the EU Emissions Trading Scheme to JI, CDM, and post- 2012 International Offsets: A Legal Analysis and Critique of the EU ETS and the Proposals for its Third Trading Period. NCCR Working Paper 2008/18.
}

\begin{abstract}
The so-called 'Linking'-Directive adopted in 2004 does not impose any limit on the import of JI/CDM credits under the European Union Emissions Trading Scheme (EU ETS), but requires from the Member States to set, in accordance with their 'supplementarity' obligations under the Marrakesh Accords, the maximal amount of Kyoto 'units' each covered installation is entitled to use for compliance under the scheme. Fearing a second price collapse of the European Union Allowance, the Commission decided, however, in 2006 to impose strict limits on the use of JI/CDM credits during the second trading period. This paper examines the legal basis of the Commission's decision and explores further the international and European legal framework within which the current debate on the use of JI/CDM credits and post-2012 international offsets takes place. It analyses in particular the recent proposal of the Commission on the third trading period of the EU ETS and the related report of rapporteur Doyle of the European Parliament and discusses the necessity to introduce quantitative and qualitative restrictions on the use of international offsets within the EU ETS against the backdrop of the international negotiations on a new global deal on climate change.
\end{abstract}


Dolsak, N. and M. Dunn. 2006. Investment in Global Warming Mitigation: The Case of “Activities Implemented Jointly.” Policy Science 39: 233-248.

\begin{abstract}
This paper examines bilateral cooperation between developed countries (home country) and developing countries (host country) to reduce greenhouse gas emissions and to enhance carbon dioxide sinks. With the home-host country pair as the unit of analysis, our logistic regression model examines 158 Activities Implemented Jointly (AIJ) investment projects from 1993 until 2002 across 2541 country-pairs. Because the marginal costs of reducing emissions may be lower in developing countries, the AIJ projects served as a policy laboratory to assess whether such investments might be advantageous to both countries in the event future regimes allowed emission credits from such bilateral projects. Instead of investing in home countries where maximum pollution reductions (or carbon sequestration) might be possible, home countries invest in locations where they can conduct their policy experiments at low transaction costs. Prior trade and aid relationships were used as a proxy. Regarding energy projects, location decisions are driven by home countries' desire to reduce air pollution that they receive from abroad. Geography - proximity of a host country to a home country - in interaction with host country's coal production, is a very important driver of location decision in AIJ energy sector projects. Location of sequestration projects is impacted by the host country's potential for avoiding deforestation as well as by previous aid and trade patterns between a home and a host country. Proximity is not important in this case.
\end{abstract}

Dutschke, M. 2000. Host Country Driven Implementation--The Case of Costa Rica. Climate Policy and Development: Flexible Instruments and Developing Countries. A. Michaelowa and M. Dutschke (eds.)

Summary: This chapter discusses first results of the AIJ pilot phase in Costa Rica. This country has a relatively high level of economic and social development and a well-developed environmental policy which is comparable to that of advanced industrial countries. It is a major destination for ecotourism. Nevertheless, it suffers from high deforestation due to unequal distribution of land, migration and cattle ranching as well as expansion of coffee and banana 
plantations. Moreover, transport emissions are rising rapidly and fossil fuel electricity generation is growing fast despite a target of phasing out fossil fuels completely.

Costa Rica's knowledge base is broad and capacity building almost not necessary. Thus, Costa Rica was able to develop creative environment policy instruments such as debt- for-nature swaps and biodiversity prospecting to attract foreign funding. It is not surprising that it was the first developing country to open a JI office, develop project approval criteria and host AIJ pilot projects. The framework for project-based climate co- operation in Costa Rica is supreme, compared to the average developing country.

Nevertheless, the success can at best described as mixed. Only a third of the projects are actually funded though several of them seem to be profitable even without a value for carbon. Most of them are proposed by US entities. To attract more funding, the JI office now certifies tradable mitigation bonds and encourages multi-sector large-scale projects where transaction costs are lower and coherence with national development objectives can be more easily checked. It directs its attention to public investors such as the US and the Norwegian government.

The renewable energy projects suffer from the unrealistic target to phase out fossil fuels by 2001 thus making AIJ projects in this sector impossible from that time. Therefore the bulk of projects concern forestry which is prone to uncertainties in calculation of emission sequestration. A comparison of the estimates shows wildly differing assumptions in baselines and sequestration capacity of the forests. Whether actual project implementation conforms to the plans remains to be seen. An independent verification of project results is being undertaken.

The analysis of the Costa Rica case shows that CDM can be only successful in the long run if the industrial countries offer incentives for investors and if baseline determination rests on a clear set of guidelines. Human and technical capacities are necessary but not sufficient conditions for successful climate co-operation projects in developing countries. They seem to be able to prevent complete project failures, though and can lead to innovative approaches. The issue will only be settled if large-scale project investment is forthcoming. Then the ability to process huge number of project proposals and check whether they conform to development priorities as well as monitoring and verification becomes crucial. 
Ellis, J., H. Winkler, J. Corfee-Morlot, and F. Gagnon-Lebrun. 2007. CDM: Taking Stock and Looking Forward. Energy Policy 2007: 15-28.

\begin{abstract}
The Kyoto Protocol's clean development mechanism (CDM) was established in 1997 with the dual purposes of assisting non-Annex I Parties in achieving sustainable development and assisting Annex I Parties in achieving compliance with their quantified greenhouse gas (GHG) emission commitments. This paper looks at the development of the CDM portfolio as well as achievements of the CDM to date in the context of wider private and public flows of investment into developing countries. These achievements include the development of 325 (by May 2005) proposed CDM projects which are together expected to generate more than 79Mt CO2-eq credits/year during 2008-2012, increasing awareness of climate change mitigation options among possible investors and others that may facilitate transactions (i.e. governments), and the strengthening of climate-relevant institutions within countries. The paper also draws lessons from this experience to date, and outlines what changes may be needed to transform the CDM concept to a broader scale after the end of the first commitment period in 2012.
\end{abstract}

\title{
Environmental Protection Agency (EPA). 2005. Greenhouse Gas Mitigation Potential in U.S. Forestry and Agriculture.
}

Excerpt from Executive Summary: This report evaluates the potential for additional carbon sequestration and GHG reductions in U.S. forestry and agriculture over the next several decades and beyond. It reports these reductions as changes from baseline trends, starting in 2010 and projected out 100 years to 2110. The report employs the Forest and Agriculture Sector Optimization Model with Greenhouse Gases (FASOMGHG). FASOMGHG is a partial equilibrium economic model of the U.S. forest and agriculture sectors, with land use competition between them, and linkages to international trade. FASOMGHG includes most major GHG mitigation options in U.S. forestry and agriculture; accounts for changes in CO2, CH4, and N2O from most activities; and tracks carbon sequestration and carbon losses over time. It also projects a dynamic baseline and reports all additional GHG mitigation as changes from that baseline. FASOMGHG tracks five forest product categories and over 2,000 production possibilities for 
field crops, livestock, and biofuels for private lands in the conterminous United States broken into 11 regions. Public lands are not included.

Fichtner, W., S. Graehl, and O. Rentz. 2003. The Impact of Private Investor's Transatction Costs on the Cost Effectiveness of Project-Based Kyoto Mechanisms. Climate Policy 3: 249-259.

\begin{abstract}
From a private investor's point of view transaction costs of project-based Kyoto mechanisms relate mainly to protect management and interaction with government representatives. However, when analyzing the cost effectiveness of project-based Kyoto mechanisms these transaction costs are often underestimated or completely ignored due to limited data availability. This paper presents an analysis of transaction costs of project-based Kyoto mechanisms by applying cost estimates from comparable activities, for example, activities implemented jointly (AIJ). The findings show that transaction costs of AIJ projects range between $7 \%$ and more than $100 \%$ of production costs with $80 \%$ of projects lying between 14 and 89\%. Furthermore the data clearly illustrate that "bigger" projects have lower specific project costs indicating the existence of economies of scale. Due to the fact that high transaction costs will push many promising projects out of the market, efforts should be undertaken to reduce transaction costs by improving procedures and business environments, for example, by standardization.
\end{abstract}

Figueres, C. 2006. Sectoral CDM: Opening the CDM to the Yet Unrealized Goal of Sustainable Development. International Journal of Sustainable Development Law and Policy 6: 5-25.

Abstract: This article advocates for the enhancement of a sectoral Clean Development Mechanism (CDM) strategy to assist developing countries in achieving their sustainable development objectives and reduce greenhouse gas emissions. After tracing the historical origins of the CDM under the Kyoto Protocol, the author observes that current CDM projects 
provide only fractious and marginal attempts at decarbonizing the global economy. The additionality clause of the Kyoto Protocol subsumes many countries' energy-friendly policies under an environmental baseline that disqualifies them from benefits and creates perverse incentives to introduce new CDM initiatives. The author reinvigorates the idea of a top-down sectoral CDM approach, whereby governments would coordinate CDM projects on a broader level and integrate climate considerations into larger economic growth policies. Under the sectoral CDM approach, the policy would in effect be the project, so progress would be measured against a situation in which the policy did not exist at all. The article outlines the benefits of such a method and the steps necessary to build the technical capacity of governments to coordinate such a project. Only through such harmonization, it is argued, can CDM projects have any meaningful effect in mitigating greenhouse gases.

Frankhauser, S. and L. Lavric. 2003. The Investment Climate for Climate Investment: Joint Implementation in Transition Countries. Climate Policy 3: 417-434.

\footnotetext{
Abstract: Transition countries are expected to become important players in the emerging market for greenhouse gas emission reductions, as they can cut emissions at a relatively low cost. However, the attractiveness of the region as a supplier of emission reductions will not only depend on its cost advantage. It will also depend on the business climate offered to carbon investors-factors like a well-functioning legal and regulatory system, economic and political stability and the capacity to process emission reduction projects efficiently. This paper looks at the carbon investment climate in the transition countries eligible for Joint Implementation (JI) Russia, Ukraine, Croatia, and the EU accession countries. It concludes that JI investors will face a clear trade-off between the scope for cheap JI on the one hand, and the quality of business environment and JI institutions on the other. The countries with the highest potential for cheap emission reductions also tend to be the countries with the most difficult business climate and the least institutional capacity for JI. The most attractive JI locations may be the median countries with a reasonable JI potential and an acceptable business climate, such as Bulgaria, Romania, and the Slovak Republic.
} 
Galik, C.S. and R.B. Jackson. 2009. Risks to Forest Carbon Offset Projects in a Changing Climate. Forest Ecology and Management 257: 2209-2216.

\begin{abstract}
When included as part of a larger greenhouse gas (GHG) emissions reduction program, forest offsets may provide low-cost opportunities for GHG mitigation. One barrier to including forest offsets in climate policy is the risk of reversal, the intentional or unintentional release of carbon back to the atmosphere due to storms, fire, pests, land use decisions, and many other factors. To address this shortcoming, a variety of different strategies have emerged to minimize either the risk or the financial and environmental implications of reversal. These strategies range from management decisions made at the individual stand level to buffers and setasides that function across entire trading programs. For such strategies to work, the actual risk and magnitude of potential reversals need to be clearly understood. In this paper we examine three factors that are likely to influence reversal risk: natural disturbances (such as storms, fire, and insect outbreaks), climate change, and landowner behavior. Although increases in atmospheric $\mathrm{CO} 2$ and to a lesser extent warming will likely bring benefits to some forest ecosystems, temperature stress may result in others. Furthermore, optimism based on experimental results of physiology and growth must be tempered with knowledge that future large-scale disturbances and extreme weather events are also likely to increase. At the individual project level, management strategies such as manipulation of forest structure, age, and composition can be used to influence carbon sequestration and reversal risk. Because some management strategies have the potential to maximize risk or carbon objectives at the expense of the other, policymakers should ensure that forest offset policies and programs do not provide the singular incentive to maximize carbon storage. Given the scale and magnitude of potential disturbance events in the future, however, management decisions at the individual project level may be insufficient to adequately address reversal risk; other, non-silvicultural strategies and policy mechanisms may be necessary. We conclude with a brief review of policy mechanisms that have been developed or proposed to help manage or mitigate reversal risk at both individual project and policy-wide scales.
\end{abstract}


Gillespie, A. 2003. Sinks and the Climate Change Regime: The State of Play. Duke Environmental Law and Policy 13.

Summary: ... The sequestration of carbon by ecosystems, particularly terrestrial environments, has been the subject of much discussion since 1990, when the method was first recognized as a way to combat climate change. ... This cycle causes the ocean to act as a carbon sink. ... The terrestrial uptake of carbon dioxide is vast. ... Indeed, although states broadly agreed to deal with sinks during the first commitment period at the 4th COP in 1998, the issue was largely postponed until the IPCC special report on land use, land-use change, and forestry (LULUCF) was ready. ... Further, for the first commitment period, any additions to or subtractions from a Party's carbon reduction obligations under the Kyoto Protocol resulting from forest management activities, could not exceed values prescribed by the COP. ... In some instances, the breakdown of leaf litter and subsequent carbon emission may actually equal the carbon uptake by the trees. ... A partial solution to this problem was arrived at during the split sessions of the 6th and 7th COPs when it was decided that in addition to counting afforestation, reforestation, and deforestation in the first commitment period, re-vegetation, forest management, cropland management, and grazing land management could also be counted. ...

Greiner, S. and A. Michaelowa. 2003. Defining Investment Additionality for CDM Projects—Practical Approaches. Energy Policy 31: 1007-1015.

\footnotetext{
Abstract: Carbon leakage is an important issue because it can reduce the environmental effectiveness of international climate agreements. Under the Kyoto Protocol, the clean development mechanism (CDM) can potentially reduce carbon leakage significantly. To what extent this potential can be realized depends on how the CDM baseline approach accounts for this effect. We use a computable general equilibrium model to analyze the impact of three different baseline approaches, and find that they produce diverging results as the number of CDM projects increase. We do, however, find that under realistic assumptions on the level of CDM activity the CDM will significantly reduce carbon leakage irrespective of which baseline approach is used.
} 
Gupta, J., P. van Beukering, H. van Asselt, L. Brander, S. Hess, and K. van der Leeuw. 2008. Flexibility Mechanisms and Sustainable Development: Lessons from Five AIJ Projects. Climate Policy 8: 261-276.

\begin{abstract}
Do 'Activities Implemented Jointly' (AIJ) projects contribute to sustainable development in the host countries? Which factors have contributed to the success or failure of the projects? Five AIJ projects were examined, accounting for $90 \%$ of the total AIJ expenditure of the Dutch government. The projects are at different stages of implementation, and four are in the process of being submitted as Clean Development Mechanism (CDM) projects. Although all five projects focused on small renewables, only one was very successful in also promoting sustainable development, while one failed completely in both achieving emissions reduction and promoting sustainable development. In this small set, the project with the most cost-effective reduction of greenhouse gases was also the project that attained the most sustainable development benefits. In order to develop successful projects that also contribute to sustainable development, it is critical that projects should be demand-driven (not only by governments, but also by involved stakeholders), designed carefully, well-documented in order to ensure institutional memory, and should aim to have a demonstrative effect.
\end{abstract}

\title{
Hahn, R.W. and G.L. Hester. 1989. Marketable Permits: Lessons for Theory and Practice. Ecology Law Quarterly 16: 361-406.
}

Excerpt from Introduction: This Article chronicles the use of marketable permits, providing a detailed comparative analysis of the application of marketable permits to environmental problems. We have three objectives: first, to provide an assessment of the performance of environmental programs that employ marketable permits; second, to analyze these programs in light of their immediate political and institutional environment, so that individual factors that influence the design and evolution of these programs can be identified; and third, to provide a framework for considering future research in the design and performance of these programs. 
Hepburn, C. 2007. Carbon Trading: A Review of the Kyoto Mechanisms. Annual Review of Environment and Resources 32: 375-393.

\begin{abstract}
The three Kyoto flexible mechanisms-emissions trading, the clean development mechanism (CDM), and Joint Implementation (JI) — have always been controversial. Proponents saw the mechanisms as clever tools to ensure environmental outcomes were achieved at least cost. Reducing the costs of compliance, they argued, would make tighter environmental targets possible, and certainly more politically feasible. Detractors have argued that the flexible mechanisms commoditize Earth's atmosphere in a manner that will allow dubious projects and the exchange of "hot air" to substitute for serious engagement on climate change. This chapter reviews the Kyoto flexible mechanisms, which will become fully operative during the period 2008 to 2012. The review assesses their progress and success to date, examines the problems that have emerged, and considers suggestions for future developments in climate policy.
\end{abstract}

\title{
Intergovernmental Panel on Climate Change (IPCC). 2001. Climate Change 2001: Mitigation. Summary for Policymakers. Report of Working Group III.
}

Introduction: This report assesses the scientific, technical, environmental, economic and social aspects of the mitigation of climate change. Research in climate change mitigation1 has continued since the publication of the IPCC Second Assessment Report (SAR), taking into account political changes such as the agreement on the Kyoto Protocol to the United Nations Framework Convention on Climate Change (UNFCCC) in 1997, and is reported on here. The Report also draws on a number of IPCC Special Reports, notably the Special Report on Aviation and the Global Atmosphere, the Special Report on Methodological and Technological Issues in Technology Transfer (SRTT), the Special Report on Emissions Scenarios (SRES), and the Special Report on Land Use, Land Use Change and Forestry (SRLULUCF). 
Jotzo, F. and A. Michaelowa. 2002. Estimating the CDM Market under the Marrakech Accords. Paper for the $3^{\text {rd }}$ CATEP workshop “Global Trading”, Kiel Institute for World Economics.

Abstract: The agreement on implementation of the Kyoto Protocol achieved at COP7 in Marrakech has important implications for investment in greenhouse gas emission reduction projects in developing countries through the Clean Development Mechanism (CDM). The required actual emission reductions for participating Annex 1 countries overall will be relatively small, as the United States do not intend to ratify the Protocol and significant amounts of carbon sequestered in domestic sinks can be credited. In addition, the potential supply of surplus emission permits (hot air) from Russia and other economies in transition may be as high as total demand in the first commitment period. Thus even under restraint of hot air sellers CDM demand will be limited, and a low demand, low price carbon market scenario appears likely.

The magnitude of the CDM will be influenced by a host of factors both on the demand and the supply side. We analyse these using a quantitative model of the global carbon market, based on marginal abatement cost curves. Implementation and transaction costs, as well as baseline and additionality rules affect the CDM's share in the carbon market. Demand for the $\mathrm{CDM}$ is sensitive to changes in business-as-usual emissions growth in participating Annex 1 countries, and also to crediting for additional sinks. Permit supply from Russia and other economies in transition is possibly the most crucial factor in the carbon market.

Kallbekken, S., L.S. Flottorp, and N. Rive. 2007. CDM Baseline Approaches and Carbon Leakage. Energy Policy 35: 4153-4163.

Abstract: Carbon leakage is an important issue because it can reduce the environmental effectiveness of international climate agreements. Under the Kyoto Protocol, the clean development mechanism (CDM) can potentially reduce carbon leakage significantly. To what extent this potential can be realized depends on how the CDM baseline approach accounts for this effect. We use a computable general equilibrium model to analyze the impact of three different baseline approaches, and find that they produce diverging results as the number of CDM projects increase. We do, however, find that under realistic assumptions on the level of 
CDM activity the CDM will significantly reduce carbon leakage irrespective of which baseline approach is used.

Kim, M.K., B.A. McCarl, and B.C. Murray. 2008. Permanence Discounting for LandBased Carbon Sequestration. Ecological Economics 64: 763-769.

Abstract: One major concern regarding land-based carbon sequestration involves the issue of permanence. Sequestration may not last forever and may either be released in the future or require expenditures to maintain the practices that keep it sequestered. In this paper, we investigate the differential value of offsets in the face of impermanent characteristics by forming a price discount that equalizes the effective price per ton between a "perfect offset" and one possessing some with impermanent characteristics. We find this discount to be a function of the future needs to replace offsets (in the face of lease expiration quantity or volatilization upon activities such as timber harvest) and the magnitude of any needed maintenance costs. We investigate the magnitude of the discounts under alternative agricultural tillage and forest management cases. In those studies, we find that permanence discounts in the range of 50\% are not uncommon. This means that in the market place an impermanent sequestration offset may only receive payments amounting to $50 \%$ of the market carbon price. Furthermore, we find that in the face of escalating carbon prices that offsets may prove to be worthless.

Korppoo, A. and A. Moe. 2008. Joint Implementation in Ukraine: National Benefits and Implications for Further Climate Pacts. Climate Policy 8: 305-316.

\footnotetext{
Abstract: Ukraine has successfully established a domestic institutional system for approving Joint Implementation (JI) projects under the Kyoto Protocol, and has shown that the system is functional by issuing approval letters. Several JI projects are being implemented in Ukraine. Project developers widely regard Ukraine as the best host country for JI projects, although the project approval system is slow and bureaucratic. Barriers were identified by this study, but the drivers of JI in Ukraine are stronger, and Ukraine has emerged as a highly competitive JI host. JI
} 
is likely to provide some support to Ukrainian participation in the future international climate regime, especially as the government is calling for the continuation of JI or other similar mechanisms to be used as a tool to finance emission reductions. This article argues that the major contribution of JI in Ukraine relates to capacity building, and the readiness of the country to participate in international climate policies in the future, rather than the financial and social benefits of JI.

Krey, M. 2005. Transaction costs of Unilateral CDM Projects in India-Results from an Empirical Survey. Energy Policy 33:2385-2397.

\begin{abstract}
Recently, transaction costs in the context of the Clean Development Mechanism (CDM) gained considerable attention as they were generally perceived to be significantly higher than for the other Kyoto Mechanisms. However, empirical evidence on the amount of transaction costs of CDM projects is very scarce. This paper presents the results from an empirical survey designed to quantify transaction costs of potential non-sink CDM projects in India. The definition of transaction costs of CDM projects was derived from recent literature and observations made in the current market for Certified Emission Reductions (CERs). During the survey, parts of transaction costs of 15 projects were quantified. An assessment of the results showed that specific transaction costs depend, to a large extent, on economies of scale in terms of total amount of CERs generated over the crediting period. Total transaction costs were quantified for seven projects. The costs range from 0.07 to 0.47 \$US/t CO2. As the projects have an emission reduction between $0.24 \mathrm{Mt} \mathrm{CO} 2$ and $5.00 \mathrm{Mt}$ CO2 over the crediting period, the results support the assumption of Michaelowa et al. (Climate Policy 3 (2003) 273) that projects with emission reductions smaller than $0.20 \mathrm{Mt} \mathrm{CO2} \mathrm{are} \mathrm{not} \mathrm{economically} \mathrm{viable} \mathrm{at} \mathrm{current} \mathrm{CER}$ prices.
\end{abstract}

Larson, D.F. and G. Breustedt. 2009. Will Markets Direct Investments Under the Kyoto Protocol? Lessons from the Activities Implemented Jointly Pilots. Environment and Resource Economics 43: 433-456. 
Abstract: Under the Kyoto Protocol, countries can meet treaty obligations by investing in projects that reduce or sequester greenhouse gases elsewhere. Prior to ratification, treaty participants agreed to launch country-based pilot projects, referred to collectively as Activities Implemented Jointly (AIJ), to test novel aspects of the project-related provisions. Relying on a ten-year history of projects, we investigate the determinants of AIJ investment. Our findings suggest that review-agency preferences related to national political objectives and possibly deeper cultural ties influenced project selection and limited the number of AIJ projects. Bilateral ties also appear to have affected investment decisions directly, possibly because of related transaction costs. The results suggest an investment process different from the assumptions that underlie well-known estimates of cost-savings related to the Protocol's flexibility mechanisms. We conclude that if approaches developed under the AIJ programs to approve projects are retained, the scale of investment under Kyoto's flexibility provisions and their cost-savings will be less than what is generally anticipated and the pattern of investment less driven by abatement costs.

\section{Lecocq, F. and P. Ambrosi. 2007. The Clean Development Mechanism: History, Status, and Prospects. The Review of Environmental Economics and Policy 1: 134-151.}

Excerpt from Introduction: Yet despite these fundamental difficulties, and despite the vagaries of the international climate negotiations in the years following the signing of the Kyoto Protocol, in less than a decade the CDM has turned into a vibrant market. In 2005 alone, more than 180 transactions were recorded, channeling $\$ 2.5$ billion of carbon finance to developing countries an amount equal to 2.5 percent of total net Official Development Assistance (ODA)(Capoor and Ambrosi 2006a). The CDM now has a large number of stakeholders, both in the North and in the South. The CDM, furthermore, has been instrumental in the involvement of developing countries in the Kyoto Protocol, an outcome that was not obvious in 1997.

The objective of this article is to review how this remarkable turn of events unfolded, to examine whether and to what extent the CDM has overcome the structural difficulties 
highlighted above, and to discuss the future of the CDM in the context of global climate mitigation in the medium and long run.

\title{
Mattoo, A., A. Subramanian, D. van der Mensbrugghe, and J. He. 2009. Reconciling Climate Change and Trade Policy. Peterson Institute for International Economics Working Paper 09-15.
}

\begin{abstract}
There is growing clamor in industrial countries for additional border taxes on imports from countries with lower carbon prices. We confirm the findings of other research that unilateral emissions cuts by industrial countries will have minimal carbon leakage effects. However, output and exports of energy-intensive manufactures are projected to decline, potentially creating pressure for trade action. A key factor affecting the impact of any border taxes is whether they are based on the carbon content of imports or the carbon content of domestic production. Our quantitative estimates suggest that the former action when applied to all merchandise imports would address competitiveness and environmental concerns in high income countries but with serious consequences for trading partners. For example, China's manufacturing exports would decline by one-fifth and those of all low and middle income countries by 8 percent; the corresponding declines in real income would be 3.7 percent and 2.4 percent. Border tax adjustment based on the carbon content in domestic production would broadly address the competitiveness concerns of producers in high income countries and less seriously damage developing country trade.
\end{abstract}

\section{McCarl, B.A. and R.D. Sands. 2007. Competitiveness of Terrestrial Greenhouse Gas Offsets: Are They a Bridge to the Future? Climatic Change 80: 109-126.}

\footnotetext{
Abstract: Activities to reduce net greenhouse gas emissions by biological soil or forest carbon sequestration predominantly utilize currently known, readily implementable technologies. Many other greenhouse gas emission reduction options require future technological development or must wait for turnover of capital stock. Carbon sequestration options in soils and forests, while
} 
ready to go now, generally have a finite life, allowing use until other strategies are developed. This paper reports on an investigation of the competitiveness of biological carbon sequestration from a dynamic and multiple strategy viewpoint. Key factors affecting the competitiveness of terrestrial mitigation options are land availability and cost effectiveness relative to other options including CO2 capture and storage, energy efficiency improvements, fuel switching, and non$\mathrm{CO} 2$ greenhouse gas emission reductions. The analysis results show that, at lower $\mathrm{CO} 2$ prices and in the near term, soil carbon and other agricultural/forestry options can be important bridges to the future, initially providing a substantial portion of attainable reductions in net greenhouse gas emissions, but with a limited role in later years. At higher CO2 prices, afforestation and biofuels are more dominant among terrestrial options to offset greenhouse gas emissions. But in the longer run, allowing for capital stock turnover, options to reduce greenhouse gas emissions from the energy system and biofuels provide an increasing share of potential reductions in total US greenhouse gas emissions.

Michaelowa, A. 2002. The AIJ Pilot Phase as Laboratory for CMD and JI. The International Journal of Global Environmental Issues 2: 260-287.

\begin{abstract}
The Activities Implemented Jointly (AIJ) program has developed about 150 greenhouse gas reduction and sequestration projects in many economic sectors in over 40 countries during the last six years. Most of these projects are rather small and many of them have only been partially implemented due to lack of finance. The lack of emissions credits is the main reason. Only half of a dozen investor countries and even less host countries have developed real national AIJ programs. The criteria of these programs have often delayed the acceptance of projects which have not really been implemented. Most of the implemented projects are commercially viable unless they have been financed by an investment subsidy. The problems of additionality and baseline determination, that manifest themselves in differing standards of baseline setting, did lead to a lot of research and proposals for methodologies. However, these methodologies have so many political implications that it has not been possible to get quick decisions on baseline rules for the CDM. Reporting has been shown to be one of the
\end{abstract}


week spots of the AIJ regime, as its quality is highly variable and data are not comparable, especially concerning costs.

\title{
Michaelowa, A. and F. Jotzo. 2003. Impacts of transaction costs and institutional rigidities on the share of the Clean Development Mechanism in the global greenhouse gas market.
}

\begin{abstract}
Transaction costs and institutional rigidities will reduce the attractiveness of the Kyoto Mechanisms compared to domestic greenhouse gas abatement options. Especially the Clean Development Mechanism (CDM) is likely to entail considerable costs of baseline development, project registration, verification and certification. The AIJ pilot phase and the PCF programme give indications about the level of these costs. Moreover, CDM projects have to be approved by host country institutions. So far, only a small share of host countries has been able to set up these institutions. Several of the larger host countries intend to only approve projects if the market price is above a certain threshold. Governments have also announced the levying of fees to finance costs of approval bodies. We model the effects of these barriers on CDM market share in the first Commitment Period of the Kyoto Protocol.
\end{abstract}

Michaelowa, A. and F. Jotzo. 2005. Transaction costs, Institutional Rigidities, and the Size of the Clean Development Mechanism. Energy Policy 33: 511-523.

\begin{abstract}
Transaction costs and institutional rigidities will reduce the attractiveness of the Kyoto Protocol flexibility mechanisms compared to domestic greenhouse gas abatement options. The clean development mechanism (CDM) in particular is likely to entail considerable costs of baseline development, project registration, verification and certification. The activities implemented jointly pilot phase and the prototype carbon fund programme give indications about these costs. There is evidence that projects with high implementation costs have high transaction costs as well. Moreover, CDM projects have to be approved by host country institutions, and so far only a small share of host countries has been able to set up these institutions. Several of the larger host countries intend to only approve projects if the market price is above a certain
\end{abstract}


threshold. Some governments will also levy fees to finance costs of approval bodies. We assess these issues using a quantitative model of the Kyoto Protocol permit market. We conclude that while changes in demand from Annex 1 countries remain the crucial factor, the size of the CDM will depend to a significant degree on transaction costs and institutional barriers in host countries.

\section{Michaelowa, A. and P. Purohit. 2007. Additionality determination of Indian CDM projects: Can Indian CDM project developers outwit the CDM Executive Board? University of Zurich, Institute for Political Science.}

A sample of 52 Indian CDM projects registered until May, 20, 2006 is analyzed with respect to the testing of additionality. While almost all projects do additionality testing, only half of them identify alternatives. Barrier testing is almost universal but only a third of the projects do an investment analysis. Small scale projects are less likely to look at the impact of CDM registration. A sub-sample of 19 projects is looked at in detail regarding barrier argumentation and treatment of the additionality test by the validators. Independent data sources are only used by one third of projects. Only about a fifth of projects provide a common practice analysis in sufficient detail. Less than half of large projects provide the relevant information on additionality in their PDD. While a technology barrier is mentioned most frequently, technology and institutional barriers, feedstock variability and lack of experience each affect a third of projects. Validators have problems in transparently evaluating barriers. The detailed case studies of two projects show that additionality assessment by the CDM Executive Board varies; if the project developer can obfuscate the attractiveness of the project, it is more likely to pass.

\section{Murray, B.C., B.A. McCarl, and H.C. Lee. 2004. Estimating Leakage from Forest Carbon Sequestration Programs. Land Economics 80: 109-124.}

Abstract: Leakage from forest carbon sequestration the amount of a program's direct carbon benefits undermined by carbon releases else- where-depends critically on demanders' ability to 
substitute non-reserved timber for timber targeted by the program. Analytic, econometric, and sector- level optimization models are combined to estimate leakage from different forest carbon sequestration activities. Empirical estimates for the United States show leakage ranges from minimal $(<10 \%)$ to enormous $(>90 \%)$, depending on the activity and region. These results suggest that leakage effects should not be ignored in accounting for the net level of greenhouse gas offsets from land use change and forestry mitigation activities.

Murray, B.C, B. Sohngen, and M.T. Ross. 2007. Economic consequences of consideration of permanence, leakage, and additionality for soil carbon sequestration projects. Climatic Change 80: 127-143.

Abstract: This paper introduces, explains, and describes methods for addressing the issues of permanence, leakage, and additionality (PLA) of agricultural soil carbon sequestration (ASCS) activities at the project level. It is important to cast these as project-level issues, because they relate to the integrity and consistency of using location-specific ASCS projects as an offset against GHG emissions generated in other sectors (e.g., energy). The underlying objective is to understand and quantify what the net carbon benefits of an ASCS project are once we account for the fact that (1) the sequestered carbon may be stored impermanently, (2) the project may displace emissions outside the project boundaries (leakage), and (3) the project's carbon sequestration may not be entirely additional to what would have occurred anyway under business-as-usual (no project) conditions. This article evaluates methods for identifying and estimating PLA and gauges the potential magnitude of these effects on the economic returns to a project.

Nussbaumer, P. 2009. On the contribution of labeled Certified Emission Reductions to sustainable development: A multi-criteria evaluation of CDM projects. Energy Policy 37: 91-101. 
Abstract: The Clean Development Mechanism (CDM) has a twofold objective, to offset greenhouse gas emissions and to contribute to sustainable development in the host country. The contribution to the latter objective seems marginal in most CDM activities. Also, CDM activities are unevenly spread among developing countries. In response to these concerns, initiatives with the objective of promoting CDM projects with broad local sustainable development dividends have been launched, such as the Gold Standard and the Community Development Carbon Fund. The Gold Standard label rewards best-practice CDM projects while the Community Development Carbon Fund focuses on promoting CDM activities in underprivileged communities. Using a multi-criteria method, the potential contribution to local sustainable development of those CDM projects with particular attributes is compared with ordinary ones. This evaluation suggests that labelled CDM activities tend to slightly outperform comparable projects, although not unequivocally.

\title{
Richards, K.R. and C. Stokes. 2004. A Review of Forest Carbon Sequestration Cost Studies: A Dozen Years of Research. Climatic Change 63: 1-48.
}

\begin{abstract}
Researchers have been analyzing the costs of carbon sequestration for approximately twelve years. The purpose of this paper is to critically review the carbon sequestration cost studies of the past dozen years that have evaluated the cost-effectiveness of the forestry option. Several conclusions emerge. While carbon sequestration cost studies all contain essentially the same components they are not comparable on their face due to the inconsistent use of terms, geographic scope, assumptions, program definitions, and methods. For example, there are at least three distinct definitions for a 'ton of carbon' that in turn lead to significantly different meanings for the metric ‘dollars per ton of carbon'. This difference in carbon accounting further complicates comparison of studies. After adjusting for the variation among the studies, it appears that carbon sequestration may play a substantial role in a global greenhouse gas emissions abatement program. In the cost range of 10 to 150 dollars per ton of carbon it may be possible to sequester 250 to 500 million tons per year in the United States, and globally upwards of 2,000 million tons per year, for several decades. However, there are two unresolved issues that may seriously affect the contribution of carbon sequestration to a greenhouse gas mitigation program,
\end{abstract}


and they will likely have counteracting effects. First, the secondary benefits of agricultural land conversion to forests may be as great as the costs. If that is the case, then the unit costs essentially disappear, making carbon sequestration a no-regrets strategy. In the other direction, if leakage is a serious issue at both the national and international levels, as suggested by some studies, then it may occur that governments will expend billions of dollars in subsidies or other forms of incentives, with little or no net gain in carbon, forests or secondary benefits. Preliminary results suggest that market interactions in carbon sequestration program analyses require considerably more attention. This is especially true for interactions between the forest and agricultural land markets and between the wood product sink and the timber markets.

Richards, K.R., R.N. Sampson, and S. Brown. 2006. Agricultural and Forestlands: U.S. Carbon Policy Strategies. Pew Center on Global Climate Change.

Excerpt from Introduction: This report reviews the available resources and considers the range of policy approaches that would include U.S. forest and agricultural lands in a domestic policy. Kenneth Richards, Neil Sampson, and Sandra Brown identify four basic policy approaches and find that different approaches are suited to different lands. The approaches also vary with regard to who bears the implementation costs - the public at large or specific groups within it —and in expected magnitude of results. For these reasons, a successful forest and agricultural lands program will require some mix of the four approaches:

- Changing practices on public lands, • Land use regulations on privately owned forestlands, • Practice-based incentives for forest and agricultural lands, and - Results-based incentives for forest and agricultural lands.

Schlamadinger, B., et al. 2007. A Synopsis of Land Use, Land Use Change, and Forestry (LULUCF) under the Kyoto Protocol and Marrakech Accords. Environmental Science and Policy 10: 271-282. 
Abstract: The complexities inherent in land use, land use change and forestry (LULUCF) activities have led to contentious and prolonged debates about the merits of their inclusion in the 2008-2012 first commitment period of the Kyoto Protocol. Yet the inclusion of these activities played a key role in agreement on the general framework of the Kyoto Protocol and LULUCF will likely continue to play a substantial part in negotiations on national commitments post-2012. The Marrakech Accords dictate which LULUCF activities are to be included under the Kyoto Protocol and provide rules on how they are to be accounted in the first commitment period. However, these rules have limitations and drawbacks that may be avoided in the structure of commitments beyond 2012. Through adherence to the objectives of the United Nations Framework Convention on Climate Change (UNFCCC), and the incorporation of several critical features, a future framework can more effectively address the mitigation challenges and opportunities of this sector.

\title{
Schneider, L. 2009. Assessing the Additionality of CDM Projects: Practical Experiences and Lessons Learned. Climate Policy 9: 242-254.
}

\begin{abstract}
The Clean Development Mechanism (CDM) under the Kyoto Protocol allows industrialized countries to use credits from greenhouse gas (GHG) abatement projects in developing countries. A key requirement of the CDM is that the emission reductions be real, measurable and additional. This article evaluates how the additionality of CDM projects has been assessed in practice. The analysis is mainly based on a systematic evaluation of 93 registered CDM projects and comes to the conclusion that the current tools for demonstrating additionality are in need of substantial improvement. In particular, the application of the barrier analysis is highly subjective and difficult to validate in an objective and transparent manner. Key assumptions regarding additionality are often not substantiated with credible, documented evidence. In a considerable number of cases it is questionable whether the emission reductions are actually additional. Based on these findings, practical recommendations for improving the assessment of additionality are provided.
\end{abstract}


Schwarze, R., J.O. Niles, and J. Olander. 2002. Understanding and Managing Leakage in Forest-Based Greenhouse-Gas-Mitigation Projects. Philosophical Transactions: Mathematical, Physical, and Engineering Sciences 360: 1685-1703.

\begin{abstract}
A major concern about land use, land-use change and forestry (LULUCF) projects under the Clean Development Mechanism (CDM) is the potential for leakage. Leak- age refers to a net increase of greenhouse-gas emissions in an area outside the project resulting from the CDM activity. This paper provides an overview of leakage, its def- initions and its causes. It describes ways that LULUCF projects may suffer from leakage and attempts to assess the magnitude of leakage risks for different LULUCF project types. It also summarizes some of the approaches, both in terms of policies and project development, to address LULUCF leakage.
\end{abstract}

Searchinger, T.D. et al. 2009. Fixing a Critical Climate Accounting Error. Science 326: 527-528.

Excerpt: The accounting now used for assessing compliance with carbon limits in the Kyoto Protocol and in climate legislation contains a far-reaching but fixable flaw that will severely undermine greenhouse gas reduction goals. It does not count $\mathrm{CO}_{2}$ emitted from tailpipes and smokestacks when bioenergy is being used, but it also does not count changes in emissions from land use when biomass for energy is harvested or grown. This accounting erroneously treats all bioenergy as carbon neutral regardless of the source of the biomass, which may cause large differences in net emissions.

Streck, C. and J. Lin. 2008. Making Markets Work: A Review of CDM Performance and the Need for Reform. The European Journal of International Law 19.

\footnotetext{
Abstract: The Kyoto Protocol's Clean Development Mechanism (CDM) is the first global market mechanism in international environmental law. It has been much lauded for its success. However, doubts whether the CDM governance structure is robust enough to meet the challenges
} 
of regulating an international market mechanism in the long term are emerging. The Executive Board (EB)'s decision-making practice is often not predictable and many of its decisions have come as a surprise to project participants and technical project experts. Members of the EB often have multiple responsibilities which result in a complicated situation of conflicting interests. Finally, private sector participants in the CDM who have been aversely affected by EB decisions have no right of recourse and essentially little if any due process rights. This article argues that incorporating mechanisms to promote procedural fairness and creating an appeals process for aggrieved CDM participants will promote transparency and accountability in the CDM decisionmaking processes. This is essential for the sound operation of the CDM regulatory regime which will have a direct positive effect on the international carbon market. After conducting a comparative analysis of other regimes in which international bodies take decisions that directly affect individuals, most notably the system of targeted sanctions of the UN Security Council and the Anti-Doping Regime, as well as examining the World Bank Inspection Panel and the European Ombudsman as models of international review mechanisms, the authors set out proposals for reform of the CDM, including professionalizing the EB and the panels, securing better and more consistent funding, the elimination of political interference, and the introduction of administrative law-like processes.

\title{
Sun, B. and B. Sohngen. 2009. Set-Asides for Carbon Sequestration: Implications for Permanence and Leakage. Climatic Change 96: 409-419.
}

\begin{abstract}
This paper examines the potential role of forest set-asides in global carbon sequestration policy. While set asides that protect forests from timber harvests and land-use conversion may alleviate concerns with permanence, and they may provide large ancillary environmental benefits, they may also lead to large leakage. This paper uses a global land use and forestry model to examine the efficiency of three crediting schemes for set-asides. The results show that if set-asides are integrated into a global forestry carbon sequestration program that includes a wide range of other management options, then 300 million hectares of land would be set-aside, and up to $128 \mathrm{Pg} \mathrm{C}$ could be sequestered in global forests by 2105 . Under alternative policies that focus exclusively on set-asides, more forestland can be set-asides, up to
\end{abstract}


3.2 billion hectare, but these policies invite large leakage in the near-term, and in the long-run, they less net carbon is removed from the atmosphere. Specifically, leakage is estimated to be 47$52 \%$, depending on the policy, and by the end of the century, up to $17 \%$ less carbon will be sequestered in all forests.

Sutter, C. and J.C. Parreno. 2007. Does the Current Clean Development Mechanism (CDM) Deliver its Sustainable Development Claims? An Analysis of Officially Registered CDM Projects. Climatic Change 84: 75-90.

\begin{abstract}
This article presents an analytical framework for analyzing Clean Development Mechanism (CDM) projects in terms of their contribution to employment generation, equal distribution of CDM returns, and improvement of local air quality. It assesses 16 officially registered CDM projects with regard to whether they fulfill the two objectives required by the Kyoto Protocol: greenhouse gas emission reductions and contribution to sustainable development in the host country. While a large part (72\%) of the total portfolio's expected Certified Emission Reductions (CERs) are likely to represent real and measurable emission reductions, less than $1 \%$ are likely to contribute significantly to sustainable development in the host country. According to our analysis, there are currently no UNFCCC registered CDM projects that are likely to fulfill the Kyoto Protocol's twofold objective of simultaneously delivering greenhouse gas (GHG) emission reduction and contributing to sustainable development.
\end{abstract}

Tavoni, M., B. Sohngen, and V. Bosetti. 2007. Forestry and the Carbon Market Response to Stabilize Climate. Energy Policy 35: 5346-5353.

Abstract: This paper investigates the potential contribution of forestry management in meeting a CO2 stabilization policy of $550 \mathrm{ppmv}$ by 2100. In order to assess the optimal response of the carbon market to forest sequestration, we couple two global models. An energy-economyclimate model for the study of climate policies is linked with a detailed forestry model through an iterative procedure to provide the optimal abatement strategy. Results show that forestry is a 
determinant abatement option and could lead to significantly lower policy costs if included. Linking forestry management to the carbon market has the potential to alleviate the policy burden of 50 ppmv or equivalently of $14 \square \mathrm{C}$, and to significantly decrease the price of carbon. Biological sequestration will mostly come from avoided deforestation in tropical-forest-rich countries. The inclusion of this mitigation option is demonstrated to crowd out some of the traditional abatement in the energy sector and to lessen induced technological change in clean technologies.

UNFCCC. 2006. Activities Implemented Jointly under the Pilot Phase: Seventh Synthesis Report. FCCC/SBSTA/2006/8.

Summary: This report provides a synthesis of the most recent information submitted for the 157 projects under the pilot phase of activities implemented jointly (AIJ). The report is based on reports submitted by Sweden on its 52 AIJ projects, including lessons learned by the country in implementing the projects, and a submission from Austria, on behalf of the European Community and member States, on general experiences with AIJ.

Wara, M.W. 2007. Is the Global Carbon Market Working? Nature Commentary 445: 595-596.

Tagline: The Clean Development Mechanism can be viewed not only as a market, but also as a subsidy and a political mechanism. Michael Wara argues that it has been most effective, so far, in achieving its political goals.

Wara, M.W. 2008. Measuring the Clean Development Mechanism's Performance and Potential. Program on Energy and Sustainable Development, Working Paper \#56.

Excerpt from Introduction: During the past 3 years, the CDM took on roughly the shape that it 
will likely have during the first commitment period of the Kyoto Protocol. The goal of this paper will be to describe in some detail what that broad outline looks like and to draw from this picture, lessons on the design of future treaty architectures and administrative legal regimes aimed at the control of GHG emissions and global warming.

This analysis builds on legal scholarship that first identified the potential of emissions trading regimes to reduce the costs of providing environmental goods and on a relatively extensive body of legal scholarship analyzing the results of attempts to design and implement emissions trading markets. Empirical work on emissions trading markets has focused on the strategic behavior of market participants, on the complicated role the regulator must play, on environmental justice problems caused by emissions trading markets, and on the difficulty of implementing the monitoring of certain air pollutants necessary for emissions trading. To date however, these analyses have focused on domestic markets. International markets, because they involve both an international regulator as well as developing country governments and firms, are likely to present both similar and unique challenges.

\section{Wara, M.W. and D.G. Victor. 2008. A Realistic Policy on International Carbon Offsets. Program on Energy and Sustainable Development, Working Paper \#74.}

Summary: As the United States designs its strategy for regulating emissions of greenhouse gases, two central issues have emerged. One is how to limit the cost of compliance while still maintaining environmental integrity. The other is how to "engage" developing countries in serious efforts to limit emissions. Industry and economists are rightly concerned about cost control yet have found it difficult to mobilize adequate political support for control mechanisms such as a "safety valve;" they also rightly caution that currently popular ideas such as a Fed-like Carbon Board are not sufficiently fleshed out to reliably play a role akin to a safety valve. Many environmental groups have understandably feared that a safety valve would undercut the environmental effectiveness of any program to limit emissions of greenhouse gases. These politics are, logically, drawing attention to the possibility of international offsets as a possible cost control mechanism. Indeed, the design of the emission trading system in the northeastern U.S. states (RGGI) and in California (the recommendations of California's AB32 Market 
Advisory Committee) point in this direction, and the debate in Congress is exploring designs for a cap and trade system that would allow a prominent role for international offsets.

This article reviews the actual experience in the world's largest offset market—-the Kyoto Protocol Clean Development Mechanism (CDM)—and finds an urgent need for reform. Welldesigned offsets markets can play a role in engaging developing countries and encouraging sound investment in low-cost strategies for controlling emissions. However, in practice, much of the current CDM market does not reflect actual reductions in emissions, and that trend is poised to get worse. Nor are CDM-like offsets likely to be effective cost control mechanisms. The demand for these credits in emission trading systems is likely to be out of phase with the CDM supply. Also, the rate at which CDM credits are being issued today—at a time when demand for such offsets from the European ETS is extremely high-is only one-twentieth to one-fortieth the rate needed just for the current CDM system to keep pace with the projects it has already registered. If the CDM system is reformed so that it does a much better job of ensuring that emission credits represent genuine reductions then its ability to dampen reliably the price of emission permits will be even further diminished.

We argue that the U.S., which is in the midst of designing a national regulatory system, should not to rely on offsets to provide a reliable ceiling on compliance costs. More explicit cost control mechanisms, such as "safety valves," would be much more effective. We also counsel against many of the popular "solutions" to problems with offsets such as imposing caps on their use. Offset caps as envisioned in the Lieberman-Warner draft legislation, for example, do little to fix the underlying problem of poor quality emission offsets because the cap will simply fill first with the lowest quality offsets and with offsets laundered through other trading systems such as the European scheme. Finally, we suggest that the actual experience under the CDM has had perverse effects in developing countries-rather than draw them into substantial limits on emissions it has, by contrast, rewarded them for avoiding exactly those commitments.

Offsets can play a role in engaging developing countries, but only as one small element in a portfolio of strategies. We lay out two additional elements that should be included in an overall strategy for engaging developing countries on the problem of climate change. First, the U.S., in collaboration with other developed countries, should invest in a Climate Fund intended to finance critical changes in developing country policies that will lead to near-term reductions. Second, the U.S. should actively pursue a series of infrastructure deals with key developing 
countries with the aim of shifting their longer-term development trajectories in directions that are both consistent with their own interests but also produce large greenhouse gas emissions reductions. 